\title{
Open Government, Technological Innovation, and the Politics of Democratic Disillusionment: (E-)Democracy from Socrates to Obama
}

\author{
OREN PEREZ
}

\section{Oren.Perez@biu.ac.il}

\begin{abstract}
There is an intriguing dissonance between the optimistic democratic vision underlying the open government movement, which seems to be driven by a belief in the transformative power of technology, and the actual achievements of the e-democracy movement in changing the praxis of democratic engagement. The present article explores this dissonance in order to develop a better understanding of the potential as well as the limits of the Internet in fostering democratic engagement. The article begins with a discussion of the competing theoretical concepts that drive the debate on open government and edemocracy, contrasting between Plato's political model in The Republic (governance by philosopher king) and the open government model, especially as envisaged by President Obama (Section II). The subsequent Sections (III-V) provide an in-depth study of three e-democracy projects involving three Canadian agencies and a transnational organization (AccountAbility). Together the three case studies expose some of the critical challenges facing the e-democracy movement. The article proceeds to develop a new model of citizenship that I term "punctuated citizenship," which seeks to capture the dissonance underlying the current edemocracy movement (Section VI). The article concludes with a discussion of the pragmatic challenges facing the open government and e-democracy projects. I argue that the
\end{abstract}

* Faculty of Law, Bar-Ilan University, Israel. Oren.Perez@biu.ac.il. July 2012. 
findings of the case studies discussed in this article, as well as preliminary assessments of Obama's OG initiative, demonstrate that the success of e-democracy projects depends on hierarchical coordination in matters that cover both technical and non-technical issues. Furthermore, this hierarchical intervention creates an agency problem that does not receive sufficient attention in the open government discourse. The open government project has to develop, I argue, new administrative law structures that can cope with the inevitable dependency of e-democratic initiatives on hierarchical ordering. I consider in this context the possible emergence of a new form of hybrid regulatory mechanisms that bring together legal institutions and web-based agents (such as computerized trust mechanisms) and examine the problems underlying this phenomenon.

\section{INTRODUCTION}

Wednesday, January 18th 2012 was a remarkable day for the ideal of Internet freedom. A massive, coordinated protest against two US anti-piracy bills, the Protect IP Act and the Stop Online Piracy Act ("PIPA" and "SOPA"), swamped the Internet. Various websites, from Google to TWiki.org, participated in the coordination of Web-petitions against the bills and in the mobilization of protest e-mails sent to the supporters of the bills in the Congress and Senate. ${ }^{1}$ Leading Internet firms also joined the protest. Wikipedia went dark for a day, leaving the statement, "Imagine a World without Free Knowledge," on its website. Mozilla similarly darkened its website adding the statement, "Protect the Internet: Help us stop Internet Censorship Legislation." Google hid its logo under a black shroud. Reddit posted the message "SOPA and PIPA damage the Internet. Today we fight back."2 The main criticism of the two bills that triggered the protest was that the

\footnotetext{
1 See GOOGLE, https://www.google.com/takeaction/past-actions/end-piracy-not-liberty/ index.html (more than 7 million people signed the Google sponsored petition); Peter Thoeny, TWiki.org Blackout to Fight Internet Censorship a Success, TWIKI.ORG (Jan. 19, 2012, 7:46 AM), https://www.google.com/takeaction/past-actions/end-piracy-not-liberty/ index.html (twiki.org had over 50,000 page views of its invitation to send a message to Congress asking his representative to vote "no" on SOPA).
}

${ }^{2}$ See The Best Sopa Protests Online - In Pictures, The GUARDIAN (Jan. 18, 2012, 12:03 PM), http://www.guardian.co.uk/technology/gallery/2012/jan/18/sopa-internetblackout-websites. 
radical enforcement powers that the bills proposed would have granted to the U.S. Government the power to "censor the Internet."3

The massive international Web-protest against the bills forced Congress and the Senate to back down from these proposals; supporters of the bill admitted that they would have to revisit their approach to IP protection. So what does this story tell us about the prospects of e-democracy? The news coverage of the protest provides a mixed answer with conflicting narratives. On one hand, the news reports have portrayed the protest as a reflection of a new form of online grass-roots activism: "individual citizens rising up" and "netizen revolt" were the terms used. 4 On the other hand, the media also referred to the protest as a reflection of a political power change. Several newspapers noted that the capacity of the new "Web Powerhouses," such as Google, Wikipedia, and Facebook to mobilize support and to quickly deliver the protest message to the people in power outweighs the lobbying power of the firms of the "old economy." 5 From this perspective, January 18th, 2012 may be seen as another powerful reflection of the development of a new netarchy, a very different Web-universe from the image of flat and free space that underlies the vision of e-democracy. ${ }^{6}$

The conflicting narratives raise a more general problem about the capacity of the Internet to facilitate enriched and extensive democratic processes. This conflict also reflects a persisting tension within the edemocracy movement between the hopes and aspirations of the proponents of Web-democracy and the actual achievements of Webbased democratic experiments. The emergence of the Internet and the

\footnotetext{
3 Mark A. Lemley et al., Don't Break the Internet, 64 (Stanford Law Review Online, Working Paper No. 1978989, 2011), available at http://ssrn.com/abstract=1978989.

4 Jonathan Weisman, In Fight Over Piracy Bills, New Economy Rises Against Old, N.Y. TimeS, Jan.18, 2012, http://www.nytimes.com/2012/01/19/technology/web-protestspiracy-bill-and-2-key-senators-change-course.html?pagewanted=all\&_r=o; Kyung Song et al., Internet's Dark Day: Anti-piracy Bills Take a Beating, SEATTLE TIMES, Jan.18, 2012, http://seattletimes.com/html/nationworld/2017274222_sopa19.html (quoting Yochai Benkler, a co-director of the Berkman Center for Internet \& Society as saying, "You've got millions of citizens who care enough to act. That's not trivial.").
}

5 Weisman, supra note 4; Song et al., supra note 4; Editorial, Web Freedom $v$ s. Web Piracy, L.A. TimES, Jan. 20, 2012, http://articles.latimes.com/2012/jan/20/opinion/la-edpiracy-20120121.

${ }^{6}$ See also Editorial, A Halt to Online Theft, BOs. HERALD, Jan,19, 2012, http:// bostonherald.com/news_opinion/opinion/editorials/2012/01/halt_online_theft (using the term cyber-bullies to describe the web-companies). 
plethora of new information and communications technologies (ICTs) associated with it have raised hopes that the Internet could reinvigorate the democratic experience and constitute a counterforce for some of the well-known maladies of twentieth century representative democracy. 7

The need for such a fix became especially poignant with social transformations at both national and transnational levels. At the national level, the pathological dependence of politicians on campaign money, the aversion of the younger population to formal professional politics, the demise of the party system as an authentic space of political engagement, and the general attention scarcity that characterizes life in the twenty-first century are all threatening to undermine the legitimacy of the contemporary democratic system with its traditional institutions of power. ${ }^{8}$ At the international level, the emergence of new transnational centers of norm-making, which are not subject to the accountability mechanisms of the state system, has created a parallel crisis of legitimization. ${ }^{9}$ The Internet was seen as a critical element of a reconstructed political-democratic structure which could better cope with the legitimization challenges facing contemporary society and could lead to the development of more inclusive and non-hierarchical political structures. ${ }^{10}$

Nevertheless, the spirit of "cyber optimism" that characterized the early days of the e-democracy movement has been replaced over the

7.JAy G. BlumleR \& Jules COlEMAN, Realising Democracy Online: A Civic Commons in Cyberspace, IPPR/Citizens Online Research Publication No. 2 - March 2001 (2001); Peter Shane, Online Consultation and Political Communication in the Era of Obama: An Introduction, in CONNECTING DEMOCRACY: ONLINE CONSULTATION AND THE FLOW OF POLITICAL COMMUNiCATION (Stephen Coleman \& Peter Shane eds., 2011).

\footnotetext{
${ }^{8}$ Matt Henn \& Nick Foard, Young People, Political Participation and Trust in Britain, 65 PARLIAMENTARY AFFAIRS 47 (2012); LAWRENCE LESSIG, REPUBLIC, LOST: HOW MONEY CORRUPTS CONGRESS-AND A PLAN TO STOP IT (2011); Michael H. Goldhaber, The Attention Economy and the Net, 2 FIRST MONDAY No. 4-7 (1997); Sarita Yardi, et al., Blogging at Work and the Corporate Attention Economy, CHI '09: PROCEEDINGS OF THE SIGCHI CONFERENCE ON HUMAN FACTORS IN COMPUTING SYSTEMS (2009).

9 Robert O. Keohane, Global Governance and Democratic Accountability, in GLoBAL Governance And Democratic ACCOUnTABILITY (D. Held \& M. Koening-Archibugi eds., 2003).

10 Manuel Castells, Global Governance and Global Politics, 38 PS: POLITICAL SCIENCE \& PoliTICS 9 (2005); Matt Leighninger, Using Online Tools to Engage-and Be Engaged by-The Public, IBM CENTER FOR THE BUSINESS OF GOVERNMENT (2011), http://www. businessofgovernment.org/sites/default/files/Using\%20Online\%20Tools\%20to\%20Engag e\%20The\%20Public_o.pdf.
} 
past decade by a more skeptical and cautious approach to the potential contribution of the Internet to democratic life. Indeed, the current literature on e-democracy is dominated by a strong sense of disillusionment. ${ }^{11}$ Earlier arguments about the capacity of ICTs to enhance the deliberative qualities of the interaction between governments and citizens were proven to be based on naïve ideological commitments that were not grounded in solid psychological and sociological models of Web-based social interactions. ${ }^{12}$ Contemporary studies on e-democracy provide a more somber picture: despite widespread experimentation with various edemocracy tools, such as online consultation, e-Wikis, e-forums, and more, the influence of ICTs on political decision-making structures has been quite negligible. ${ }^{13}$ To a large extent the early optimism of cyber-democrats could be attributed to technological determinism, which assumed that putting the right platform in place would guarantee that the public would come and engage in civic participation of the scale and depth imagined by the ideal model of electronically-mediated deliberative democracy.

Paradoxically, despite this relative disillusionment about the capacity of the Internet to fulfill its promise, governments, international organizations, and non-governmental organizations continue to develop and invest in e-democracy initiatives. Probably the most prominent initiative is President Obama's "Open Government Directive" (OG Directive), developed in response to a presidential order he signed on his first day in office. ${ }^{14}$ The directive

11Alina Ostling, ICT in Politics: From Peaks of Inflated Expectations to Voids of Disillusionment, 9 EUROPEAN JOURNAL OF EPRACTICE (2010), http://www.epractice.eu/ files/European\%20Journal\%20epractice\%20Volume\%209.4.pdf; I. KoTSIOPOULOS, BRINGING TOGETHER AND ACCELERATING EGOVERNMENT RESEARCH IN THE EU: EDEMOCRACY REPORT (2009), http://www.epractice.eu/files/edemocracy.pdf.

12 David Coursey \& Donald F. Norris, Models of E-Government: Are They Correct? An Empirical Assessment, 68 PUB. ADMIN. REV. 523, 532 (2008).

13 BeAte KoHLER-Koch, Does Participatory Governance Hold its Promises?, in EFFICIENT AND DEmocratic GovernanCE In THE EuRopean UNION 265, 283 (Beate Kohler-Koch \& Fabrice Larat eds., 2008); Lincoln Dahlberg, Re-constructing Digital Democracy: An Outline of Four 'Positions', 13 NEw MEDIA \& SOC'Y 855, 866 (2011); ÅKE GRÖNLUND \& JOACHIM ÅSTRÖM, DoIT Right: Measuring Effectiveness of Different eConsultation Designs, in ELECTRONIC PARTICIPATION: FIRST INTERNATIONAL CONFERENCE, EPART 2009, LinZ, AUSTRIA, SEPTEMBER 1-3, 2009 PROCEEdINGS 98 (Ann Macintosh \& Efthimios Tambouris eds., 2009).

14 See OFFICE OF MgMT. \& Budget, M10-06, MEMORANDUM For THE HEADS OF EXECUTIVE DEPARTMENTS AND AGENCIES (2009), available at $h \mathrm{ttp}: /$ www.whitehouse.gov/sites/ default/files/omb/assets/memoranda_2010/m10-06.pdf. 
was based on three principles: transparency, participation, and collaboration. The OG Directive has generated a frenzy of activity within the U.S. government, including the opening of unique "open government" portals by different branches of the U.S. government, the establishment of a new open data portal that provides single-point access to high-value data from various federal agencies, ${ }^{15}$ the continuous development of Regulations.gov, the creation of an Open Government Dashboard, which tracks progress across the government, and the development of Challenge.gov, which is an innovative tool used by government to challenge citizens with pending regulatory dilemmas. ${ }^{16}$

The "Open Government" idea has had a strong transnational impact. The Canadian government initiated an open government project that is being pursued through three main streams: Open Data, Open Information and Open Dialogue. The Open Dialogue stream builds on the "Consulting with Canadians" portal, which seeks to develop web-mediated consultation opportunities across the Canadian government (explored in more detail in Section III below). ${ }^{17}$ The U.K. government developed several initiatives that draw on the open government model including an open data portal and a novel epetition system. ${ }^{18}$ The Australian government has issued a Declaration of Open Government in which it has committed "to open government based on a culture of engagement, built on better access to and use of government held information and sustained by the innovative use of technology." 19 In Israel, there have been several experiments with e-

\footnotetext{
${ }^{15}$ As I will argue below there is a strong association between the e-democracy movement and the more general drive toward increased transparency in the public arena.

${ }^{16}$ See also Open Government Initiative, THE WHITE HOUSE, http://www.whitehouse.gov/ open/about/initiatives (last visited Jan. 25, 2013).

17 Open Dialogue, OPEN GOVERNMENT, http://www.open.gc.ca/open-ouvert/dialogueeng.asp (last accessed Apr. 11, 2012).

18 Opening Up Government, HM GOVERNMENT, http://data.gov.uk (last visited Jan. 26, 2013); E-Petitions-Create and Sign Petitions Online, HM GOVERNMENT, http://epetitions. direct.gov.uk (last visited Jan. 26, 2013) (The e-petition system provides citizens the opportunity to create an e-petition, which is eligible for debate in the House of Commons if it collects 100,000 signatures).

19 Lindsay Tanner, Declaration of Open Government, AUSTRALIAN GOVERNMENT, DEPRATMENT OF FINANCE AND DEREGULATION (July 16, 2010), http://agimo.gov.au/2010/ 07/16/declaration-of-open-government.
} 
democracy, initiated by both the government and the civic society. ${ }^{20}$ The Open Government Declaration (OG Declaration) that was signed on September 2011 by eight countries provides a further indication to the international spread of the open government vision. ${ }^{21}$ Experiments in web-based open government projects can also be found in varied transnational organizations such as the World Bank, ISEAL Alliance, AccountAbility and the International Council on Nano Technology. ${ }^{22}$

There is a dissonance between the optimistic vision underlying these multiple initiatives, which seems to be driven by a combination of pro-democratic sentiments and a belief in the transformative power of technology, and the actual achievements of the e-democracy movement in reformulating the praxis of democratic engagement. The present article explores this dissonance in order to develop a better understanding of the potential and limits of the Internet in fostering intensive processes of democratic engagement. It focuses, in particular, on the capacity of Web-based mechanisms to facilitate reflexive and epistemologically complex deliberative processes that go beyond non-deliberative mechanisms such as voting, e-petitions and the Facebook 'like' button.

I begin with a discussion of the competing theoretical concepts that drive the debate on open government and e-democracy (Section II below). The discourse on e-democracy creates a highly contested domain that brings together contrasting metaphysical, normative, and pragmatic commitments. In this Section, I seek to elucidate these conflicting commitments and to clarify the normative and pragmatic

${ }^{20}$ See ISRAEL GOVERNMENT PORTAL (Jan. 1, 2013), http://www.shituf.gov.il; HidAVRUT, http://hidavrut.gov.il (last visited Jan. 26, 2013); J14, http://j14.org.il (last visited Jan. 26, 2013); OPEN KNESSET, http://oknesset.org (last visited Jan. 26, 2013).

${ }^{21}$ See Open Government Declaration, OPEN GOVERNMENT PARTNERSHIP (Sept., 2011), http://www.opengovpartnership.org/open-government-declaration (acknowledging "that people all around the world are demanding more openness in government. They are calling for greater civic participation in public affairs, and seeking ways to make their governments more transparent, responsive, accountable, and effective."). The signatories are Brazil, Indonesia, Mexico, Norway, Philippines, South Africa, the United Kingdom, and the United States. Id.

22 See World Bank ICT Sector Strategy, http://web.worldbank.org/WBSITE/EXTERNAL/ TOPICS/EXTINFORMATIONANDCOMMUNICATIONANDTECHNOLOGIES/o,,content MDK:23118048 menuPK:8432091 pagePK:210058 piPK:210062 theSitePK:282823,00 .html; The ISEAL Assurance Code Consultation Opens, ISEAL ALLIANCE (Nov. 2, 2011), http://digitalmedia.worldbank.org/projectsandops/consultations.htm; Standards, ACCOUNTABILITY, http://www.accountability.org/standards/index.html (last visited Jan. 26, 2013); GOODNANOGUIDE (Nov. 1, 2011), http://goodnanoguide.org/HomePage. 
challenges facing the e-democracy project. This clarification is necessary before we delve into the manifold socio-technical details involved in the implementation of e-democracy schemes. In this context, I contrast between two political models that lie at the core of the debate on e-democracy and open government. The first model was developed by Plato in The Republic, governance by the "philosopher king," which in its contemporary formulation is associated with the increasing powers of the experts of the state bureaucracy. The second model is the open governance structure envisaged in the various open government initiatives described above. I suggest that the open government vision can find support in the writings of another prominent philosopher, Karl Popper, especially in the ideas developed in his book, The Open Society and Its Enemies.

The subsequent Sections (III and IV) provide an in-depth study of three e-democracy projects involving different institutional structures and players. The first project I study is the Canadian Government's Consulting with Canadians project, which exposes the challenges of developing online consultation projects in a gigantic bureaucratic environment. ${ }^{23}$ The second case study focuses on the experience of TransLink, the South Coast British Columbia Transportation Authority, with digital democracy. In contrast to the experience of the Canadian Federal Government, this project provides insight into the dynamic of a smaller organization with a more innovative institutional culture. The third case study (Section IV) takes a closer look at a Wikibased consultation process conducted in 2009-2010 by AccountAbility, a transnational non-governmental organization (NGO) dealing with corporate responsibility and sustainable development. It provides an opportunity to examine democratic processes at the transnational level and the challenges of using Wiki technology. Together the three case studies expose some of the critical challenges facing the e-democracy movement. Section $\mathrm{V}$ discusses the lessons of the three case studies.

Section VI develops a new model of citizenship that I term "punctuated citizenship." The idea of "punctuated citizenship" seeks to capture the tension between the idealistic vision of e-democracy and the actual performance of e-democracy projects. The Section starts with an empirical evaluation of the achievements of Obama's Open Government Initiative, which leads me to the more theoretical discussion of "punctuated citizenship." Section VII concludes with a

\footnotetext{
23 Shane, supra note 7, at 3 ("“Online consultations' refers to 'Internet-based discussion forums that represent government-run or at least government-endorsed solicitations of public input with regard to policy making”).
} 
discussion of the pragmatic challenges facing the open government and e-democracy projects. The Section highlights several strategies that respond to the challenge of punctuated citizenship, drawing on the lessons of the case studies. It then proceeds to explore some of the novel regulatory challenges raised by the development of digital deliberation formats. These challenges relate, in particular, to the way in which the success of e-democracy projects depends on hierarchical coordination in matters that cover both technical and non-technical issues. This hierarchical intervention creates, I argue, an agency problem that does not receive sufficient attention in the open government discourse. I conclude the article with a discussion of the challenge of developing new administrative law structures, which can cope with the inevitable dependency of e-democratic initiatives on hierarchical ordering. This challenge produces new politics of disillusionment-a perpetual tension between the hierarchical intervention that is prerequisite for the emergence of free deliberation and the need to put the hidden technical and sociological selections associated with this intervention to public scrutiny. Coping with this tension requires, I argue, the development of novel administrative law structures. I consider in this context the possible emergence of a new form of hybrid regulatory mechanisms that brings together legal institutions and web-based agents, and I examine the problems underlying this phenomenon.

\section{E-DEMOCRACY AS A CONTESTED CONCEPT}

\section{A. Mapping the Terrain: Obama, Socrates, and the Ideal of Open Government}

The discourse on e-democracy creates a highly contested domain that brings together contrasting metaphysical, normative, and pragmatic commitments. It involves competing conceptions of democracy and citizenship, entangled in a complex network of legal doctrines, political practices, and cultural narratives. This Section seeks to unfold this contested domain and clarify the normative and pragmatic challenges facing the e-democracy project. This clarification is necessary before we delve into the multiple socio-technical details involved in the implementation of concrete e-democracy projects. I wish to start this journey by contrasting two political models that lie at the core of the debate on e-democracy and open government. At one end is the political model of governance by the philosopher king developed by Plato in The Republic. At the other end is the model of 
"open government," which can be supported by the writings of one of the fiercest modern critics of the Platonic model, Karl Popper.

Plato's writings in The Republic ${ }^{24}$ challenge what is probably the key normative commitment underlying the ideas of e-democracy and open government: the claim that the citizen-body as a whole should be given meaningful opportunities to take part in the political process. Plato argued that political power should be bestowed upon those who possess knowledge of what is good for themselves and for others, ${ }^{25}$ even if the elite section of philosophers constitutes a minority, as Socrates explains:

[W] hen a community is founded on natural principles, the wisdom it has as a whole is due to the smallest grouping and section within it and to the knowledge possessed by that group, which is the authoritative and ruling section of the community. And we also find that this category, which is naturally the least numerous, is the one which inherently possesses the only branch of knowledge which deserves to be called wisdom. ${ }^{26}$

Plato's political model is not totalitarian in the Orwellian sense; it does not claim that the purposes and well-being of individuals should be subordinated entirely to the goals of the state. ${ }^{27}$ It is rather a form of enlightened paternalism, as evident from Plato's discussion of

\footnotetext{
${ }^{24}$ Unlike modern philosophers Plato's writings do not provide a coherent argument. Their dialogical form-with Socrates as the main figure-makes it difficult to extract a distinct coherent argument from the various works. Further there is also some controversy as to which dialogues represent the view of Socrates and in which Socrates serves as a mouthpiece for Plato. See also Daniel W. Graham, Socrates and Plato, 37 PHRONESIS 141 (1992); T. H. IRWIN, The Platonic Corpus, in THE OXFORD HANDBOOK OF PLATO 79 (Gail Fine ed., 2008) (There is, however, broad consensus that the Republic represents the views of Plato).

${ }_{25}$ Book V of The Republic argues that the knowledge needed for ruling is the knowledge of Forms-a knowledge of things in themselves, of that which is invariable and permanent (e.g., justice)-and that this knowledge is out of the reach for most people. DOMINIC SCOTT, The Republic, in THE OXFORd HandBOOK OF Plato 373 (Gail Fine ed. 2008); Plato, REPUBLIC 203, 484b-e (Robin Waterfield trans., Oxford University Press 1993).

26 PLATO, supra note 25, at 135, 429a.

27 C. C. W. Taylor, Plato's Totalitarianism, in PLATo's REPUBLIC 31 (Richard Kraut ed. 1986); Ellen Meiksins Wood \& Neal Wood, Socrates and Democracy: A Reply to Gregory Vlastos, 14 POL. THEORY 55 (1986) (on the undemocratic aspects of Socrates' thought).
} 
idealized slavery. Speaking about the producers section in the community Socrates notes:

The question is, how can a person in this condition become subject to the kind of rulership which is available to a truly good person? By being the slave, we suggest, of a truly good person, whose divine element rules within him. But we're not suggesting . . . that his status as a subject should do him harm; we're saying that subjection to the principle of divine intelligence is to everyone's advantage. It's best if this principle is part of a person's own nature, but if it isn't, it can be imposed from outside, to foster as much unanimity and compatibility between us as might be possible when we're governed by the same principle. ${ }^{28}$

Despite the seeming gap between Plato's model and contemporary conceptions of constitutional democracy, his paternalistic vision of rule by the elite remains highly relevant to contemporary political debates. Plato's philosopher king was replaced by the mythical figure of the "expert," who, like Plato's philosopher, bases his claim to power on privileged epistemological capacities, a product of academic education and pragmatic experience. ${ }^{29}$ There is strong linkage between Plato's vision of a polity governed by philosophers and the skepticism of contemporary scholars regarding the capacity of ordinary citizens to take part in the complex governance of the modern state. ${ }^{\circ}$ Contemporary society is faced with formidable

\footnotetext{
${ }^{28}$ PLATO, supra note 25 , at 340, 590d.

${ }^{29}$ As Bernard Schwartz wrote in 1978: "In large part, too, the role of the philosopher-king has been assumed by the modem administrative expert. His position is elevated and aggrandized in a society of insecure laymen. His is the voice with the ready answer. His opinions become the facts upon which lesser mortals-laymen-risk life and fortune"'. Bernard Schwartz, Of Administrators and Philosopher-Kings: The Republic, the Laws, and Delegations of Power, 72 Nw. U. L. REv. 443, 449 (1978).

30 For a modern skeptic approach of the capacity of lay citizens to contribute to regulatory decisions, see, e.g., Douglas J. Sylvester, et al., Not Again! Public Perception, Regulation, and Nanotechnology, 3 REGULATION \& GOvERNANCE (2009); Jeffrey J. Rachlinski, Cognitive Errors, Individual Differences , and Paternalism, 73 U. CHI. L. REv. 207 (2006). Rachlinski is particularly blunt. He argues that if predictable groups of people avoid making the errors that others commit, then law should account for such differences. He suggests three parameters that might distinguish people who can avoid error: cognitive ability, experience and training, and demographic variables. Thus, he argues, legal scholars
} 
challenges-international terror, volatile financial markets and uncertain environmental risks-which seem beyond the capacity of ordinary citizens. From this perspective, participatory and transparency mechanisms have at most an educational and appeasing function; they cannot (and should not be expected to) improve the epistemic credibility of the administrative technocracy.

The open government and e-democracy movements are based on a completely different vision of democracy and citizenship, which places much more faith in the capacity of citizens to contribute to the political process, but also considers the opening up of the political machine to citizen participation as a necessary element of a legitimate political regime. Democratic theory offers two primary responses to the arguments of Plato and his contemporary successors. The first response is metaphysical: it questions the claim about the existence of privileged access to knowledge-of the philosopher king in the Republic or of the administrative expert in today's technocracy. ${ }^{31}$ This argument reflects a deep-seated disillusionment with the governance model of hierarchical bureaucracies. ${ }^{32}$ This critique is commonly coupled with the idea of collective wisdom, ${ }^{33}$ which suggests that civic participation can lead to better decisions through two different mechanisms. First, it has epistemic value because of its capacity to facilitate collaborative knowledge production, and second, it provides an external check on the bureaucratic process. Obama's OG Directive clearly adopts this view by stating: "Participation allows members of the public to contribute ideas and expertise so that their government can make policies with the benefit of information that is widely dispersed in society." 34

interested in the application of psychology to law would do well to consider the possibility that an identifiable group will avoid cognitive errors.

${ }^{31}$ Taylor, supra note 27, at 9.

${ }^{2}$ See Donald P. Moynihan, Normative and Instrumental Perspectives on Public

Participation, 33 AMERICAN REVIEW OF PUblic AdMINISTRATION 164, 167 (2003).

33 Reference to Wikipedia seems appropriate at this context; see Collective Wisdom, WIKIPEDIA, http://en.wikipedia.org/wiki/Collective_wisdom (last accessed Aug. 24, 2012); The Wisdom of Crowds, WIKIPEDIA, http://en.wikipedia.org/wiki/The_Wisdom_of_ Crowds (last accessed Jan. 26, 2013).

34 OfFICE OF MGMT. \& BUDGET, supra note 14, at 1. Similarly the Open Government Declaration of the Open Government Partnership states that "[p]ublic engagement, including the full participation of women, increases the effectiveness of governments, which benefit from people's knowledge, ideas and ability to provide oversight." Open Government Declaration, supra note 21. 
The second response to Plato's argument is moral. It rejects the claim that knowledge confers political authority, arguing that this approach denies the value of autonomy as a constituent of human welfare and a perquisite for a just society. 35 The linkage between regulatory openness and legitimacy is recognized implicitly by the OG Directive. First, the government's commitment to openness is depicted as a non-contingent obligation that is not dependent upon instrumental considerations. Second, the recognition of the independent moral value of the commitment to openness is also implicit in the way in which the OG Directive invokes the concept of accountability. ${ }^{36}$ In this context, the idea of accountability can make sense only as a non-instrumental commitment to a government structure in which the citizens are considered the constitutive source of the government's authority and are therefore entitled to hold it accountable for its actions. 37

The foregoing metaphysical and normative elements of the justification of democracy find support in Karl Popper's book, The Open Society and Its Enemies. For Popper, knowledge is intrinsically and inevitably a product of a collective process of critical debate and argumentation. Popper defines rationalism as practical attitudes: "Rationalism is an attitude of readiness to listen to critical arguments and to learn from experience .... [I]t is fundamentally an attitude of admitting that ' $I$ may be wrong and you may be right, and by an

35 Taylor, supra note 27.

${ }^{36}$ The OG Directive notes, "To create an unprecedented and sustained level of openness and accountability in every agency, senior leaders should strive to incorporate the values of transparency, participation, and collaboration into the ongoing work of their agency." OFFICE OF MGMT. \& BUDGET, supra note 14, at 4. The idea of accountability is similarly invoked in the OG Declaration. Open Government Declaration, supra note 21 . The idea of accountability refers to the need of a power-holder to have to answer for her action or inaction and to be exposed to potential sanctions. Robert $\mathrm{O}$. Keohane, The Concept of Accountability in World Politics and the Use of Force, 24 MICH. J. INT'L L. 1121, 1124 (2003). Mulgan emphasizes the nexus between systems of accountability and the democratic principle that the government-through all its branches-should be responsive to demands of the wider public. Richard Mulgan, 'Accountability': An Ever-Expanding Concept?, 78 PUBLIC ADMINISTRATION 555, 559 (2000).

${ }_{37}$ The OG Directive (and similarly the OG Declaration) provides the means through which citizens can hold their government accountable; however neither of these texts condition this commitment on the factual question of whether citizens would actually use the data released through open government schemes for that purpose. 
effort, we may get nearer to the truth." 38 The "attitude of reasonableness," as he labels it, "is very similar to the scientific attitude, to the belief that in the search for truth we need co-operation, and that, with the help of argument, we can in time attain something like objectivity." 39 Popper explicitly rejects the Platonic claim that privileged access to knowledge could be a ground for political authority:

The position here adopted is very different from the popular, originally Platonic, view of reason as a kind of 'faculty', which may be possessed and developed by different men in vastly different degrees. Admittedly, intellectual gifts may be different in this way, and they may contribute to reasonableness; but they need not. Clever men may be very unreasonable; they may cling to their prejudices and may not expect to hear anything worthwhile from others. According to our view, however, we not only owe our reason to others, but we can never excel others in our reasonableness in a way that would establish a claim to authority; authoritarianism and rationalism in our sense cannot be reconciled, since argument, which includes criticism, and the art of listening, is the basis of reasonableness. Thus rationalism in our sense is diametrically opposed to all those modern Platonic dreams of brave new worlds in which the growth of reason would be controlled or 'planned' by some superior reason. Reason, like science, grows by way of mutual criticism; the only possible way of 'planning' its growth is to develop those institutions that safeguard the freedom of this criticism, that is to say, the freedom of thought. $4^{\circ}$

\footnotetext{
38 Karl Popper, The Open Society ANd Its Enemies Vol. II, at 213 (Princeton Univ. Press rev. ed. 1971) (1945) (emphasis in the original), available at http://ia600307.us.archive. org/20/items/opensocietyandito33064mbp/opensocietyandito33064mbp.pdf.

39 Id. at 213.

$40 \mathrm{Id}$. at 214.
} 
The old political debate between Plato and Popper resurfaces in the contemporary debate on e-democracy and open government as an opposition between two narratives: the ideal of "informed citizenship" and the more somber conception of politics based on "low information rationality." The ideal of "informed citizenship" plays a pivotal role in the doctrinal apparatus of modern administrative law. ${ }^{41}$ The concepts of civic participation and deliberation, as articulated in current administrative law doctrines, ${ }^{42}$ are based on the expectation that citizens who take part in political interaction would make their political contributions in an epistemologically responsible way. The paradigm of the "informed citizen" received its most powerful representation in the doctrine of transparency, which has become one of the hallmarks of modern administrative law. 43 It is also a key pillar of the "Open Government" model.

${ }^{41}$ Francesca Bignami, Three Generations of Participation Rights in European Administrative Proceedings (Jean Monnet Working Paper 11/03, 2003), available at http://centers.law.nyu.edu/jeanmonnet/archive/papers/03/031101.pdf; Richard B. Stewart, Administrative Law in the Twenty-First Century, 78 N.Y.U. L. Rev. 437, 444 (2003).

${ }^{42}$ Nicola Hartley \& Christopher Wood, Public Participation in Environmental Impact Assessment--Implementing the Aarhus Convention, 25 ENVIRONMENTAL IMPACT ASSESSMENT REVIEW 319 (2005).

43 Prominent examples are, in the U.S., the Freedom of Information Act (1966) and the Electronic Freedom of Information Act Amendments of 1996, in Canada, the Access to Information Act (1983) and in the EU, Regulation (EC) No 1049/2001 of the European Parliament and the Council of 30 May 2001 regarding public access to European Parliament, Council and Commission documents; See also Review on the Rules on Access to Documents, EUROPA, http://ec.europa.eu/transparency/revision/index_en.htm (last visited Jan. 25, 2013). The EU Commission and European Parliament have recently launched a Joint Transparency Register to shed light on all those seeking to influence European policy. Transparency Register, EUROPA (Nov. 27, 2012), http://europa.eu/ transparency-register/index_en.htm; Transparency, EUROPEAN COMMISSION (Dec. 12, 2012), http://ec.europa.eu/transparency/index_en.htm; See also Cary Coglianese, The Transparency President? The Obama Administration and Open Government, 22 GOVERNANCE: AN INTERNATIONAL JOURNAL OF POLICY, ADMINISTRATION, AND INSTITUTIONS 529 (2009), available at http://papers.ssrn.com/sol3/papers.cfm?abstract_id=1433815; David C. Vladeck, Information Access-Surveying the Current Legal Landscape of Federal Right-to-Know Laws, 86 TEx. L. REV. 1787 (2008); The principle is also an integral part of Global Administrative Law. See Benedict Kingsbury, et al., The Emergence of Global Administrative Law, 68 LAW \& CONTEMP. PROBS. 15 (2005); See, e.g., UNITED NATIONS ECON. COMM'N FOR EUROPE, THE AARHUS CONVENTION ON ACCESS TO INFORMATION, PUBLIC ParTiCIPATION IN DECISION MAKING AND ACCESS TO JUSTICE IN ENVIRONMENTAL MATTERS (June 25, 1998), available at http://www.unece.org/fileadmin/DAM/env/pp/documents/ cep43e.pdf; WORLD TRADE ORG., WTO TRADE POLICY REVIEW MECHANISM, available at http://www.wto.org/english/docs_e/legal_e/29-tprm.pdf. 
The regulatory endorsement of the ideal of "informed citizenship" reflects a dual normative commitment. Institutionally, this endorsement reflects the belief that the legitimacy of political decisions depends on their capacity to satisfy certain procedural requirements of openness and inclusiveness as well as the more substantive requirements of dialogical responsiveness and epistemological responsibility. 44 Individually, these commitments articulate a new model of the "good citizen"-engaging, curious, and epistemologically adept. Unlike Plato's political vision, this normative conceptualization is driven by an implicit belief in the cognitive capacity of the modern citizen to fulfill these expectations in a manner that at least comes close to the normative expectations.

But the paradigm of "informed citizenry" and the administrative practices driven by it-participatory and disclosure schemes and their online articulations-seem to be in tension with the reality of twentyfirst century politics. First, as argued by various political theorists such as Michael Schudson, Samuel Popkin, Arthur Lupia, and Doris Graber, the model of "informed citizenship" seems to ignore the extent to which contemporary democracy is based on "low information rationality." 45 There is broad evidence demonstrating that citizens perform their political obligations on the basis of a lowinformation diet, supported by an array of decision shortcuts. This argument questions the feasibility of creating epistemologically demanding deliberative structures of the type envisioned by the Open Government vision. It highlights instead the important role of political intermediaries in the democratic process: political parties, civic groups, unions, religious leaders, mass-media, academics, and corporations. The skeptical approach of these thinkers draws on three inter-related barriers to wide-ranging democratic engagement: epistemic scarcity, attention scarcity, and motivational scarcity. $4^{66}$ The flat, legal articulation of civic engagement (concerning both knowledge acquisition and active participation) in the doctrinal

\footnotetext{
44 Jennifer M.P. Stewart \& A. John Sinclair, Meaningful Public Participation in Environmental Assessment: Perspectives from Canadian Participants, Proponents, and Government, 9 J. OF ENVTL. ASSESSMENT POLICY AND MGMT. (JEAPM) 161, 173-74 (2007).

45 Samuel L. Popkin, The REaSoning Voter: Communication and PERSUASION IN PRESIDENTIAL CAMPAIGNS 7 (University of Chicago Press. 1991); Doris Graber, Mediated Politics and Citizenship in the Twenty-First Century, 55 ANN. REV. OF PSYCHOL. 545, 563 (2004).

${ }^{46}$ See Oren Perez, Complexity, Information Overload and Online Deliberation, 5 ISJLP 43 (2009).
} 
structures of modern administrative law ignores this multifaceted social scarcity and the way in which contemporary forms of protest and voice, which emerge outside the legally-sponsored venues of participation (both online and offline), overcome these barriers. ${ }^{47}$

\section{B. The Challenge of E-Democracy: A Pragmatic Outlook}

Is there a way to resolve the tension between Obama and Popper on one hand, and Plato on the other? In the concluding Section of this article, I develop the idea of "punctuated citizenship" as a middle ground between these two opposing visions. But at this point I want to elucidate the practical challenges facing the e-democracy and open government project-challenges well-framed by the Plato-Popper debate.

The moral and instrumental justifications for democratic governance of the type imagined by Obama and Popper suggest two criteria for evaluating Web-based democratic schemes, focusing on their capacity to facilitate socially encompassing and epistemologically complex processes of deliberation and reflection. The first criterion emphasizes the inclusiveness of the process: it questions the extent to which political discussion has considered all the relevant issues and provided a voice for all the relevant stakeholders. "Relevance" can be defined in this context either through the perspective of the participants or in view of some external normative criteria. The second criterion refers to the responsiveness of the dialogical process. 48 "Responsiveness" refers to the extent to which the discussion addresses all the relevant questions and objections raised by the participants, leading to a decision that is reasonably justified and not arbitrary. Reasonable justification is not a measure of logical correctness, but rather represents the cogency of the decision-that is, its discursive responsiveness. ${ }^{49}$ Responsiveness also includes the effect of the deliberative process on the ultimate political decision. A

\footnotetext{
47 Scott P. Robertson, et al., Off the Wall Political Discourse: Facebook Use in the 2008 U.S. Presidential Election, 15 INFORMATION POLITY 11 (2010); Weiwu Zhang, et al., The Revolution Will be Networked, 28 SocLAL SCIENCE COMPUTER REVIEW 75 (2010); Jessica Vitak, et al., It's Complicated: Facebook Users' Political Participation in the 2008 Election, 14 CyBerPSYCHOLOGY, BEHAVIOR, AND SOCIAL NETWORKING 107 (2011).
}

${ }^{48}$ William Rehg, et al., Computer Decision-Support Systems for Public Argumentation: Assessing Deliberative Legitimacy, 19 AI \& SOC'Y 203, 216 (2005).

$49 \mathrm{Id}$. An arbitrary decision would be a decision that disregards some considerations or voices which were relevant to the decision. 
deliberative process that carries no influence on the rules or policies which are ultimately adopted by the responsible authority cannot be considered "responsive" in any meaningful sense.

By highlighting human cognitive and attentive limitations and the motivational barriers associated with political engagement, especially in epistemologically demanding deliberative processes, the Platonic arguments challenge the capacity of e-democracy schemes to meet these dual criteria. In particular these arguments challenge any technologically deterministic hope that e-democracy can evolve by simply providing the "right" Web platform. This critique points out two inter-related challenges for the e-democracy movement. The first challenge is technological and focuses on the capacity of new ICTs to enable citizens to reach beyond their inherent cognitive and attentive limitations. Four types of technologies are particularly important in this context:

1. Sophisticated search technologies drawing on the vision of the Semantic Web. ${ }^{\circ}$

2. Web 2.0 user-sensitive, interactive technologies..$^{11}$

3. New visualization techniques to support online consultation. ${ }^{2}$

4. Deliberation and support technologies, such as Wiki platforms.53

\footnotetext{
${ }^{50}$ See, e.g., Thomas Baker et al., Semantic Web Case Studies and Use Cases, W3C (June 13, 2012, 6:49 AM), http://www.w3.org/2001/sw/sweo/public/UseCases.

${ }_{51}^{1}$ See Paul Macmillan, Andrew Medd \& Peter Hughes, Change Your World or the World Will Change You: The Future of Collaborative Government and Web 2.o, DELOITTE (2008), http://www.deloitte.com/assets/Dcom-Canada/Local\%20Assets/Documents/ ca_govt_web20_maro8_EN.pdf; OECD, PARTICIPATIVE WEB AND USER-CREATED CONTENT: WEB 2.0, WIKIS AND SOCIAL NETWORKING (2007), available at http://browse. oecdbookshop.org/oecd/pdfs/free/9307031e.pdf; Michael Zimmer, Critical Perspectives on Web 2.O, 13 FiRST MONDAY (SPECIAL IsSUE) 3 (2008).

${ }_{52}^{2}$ M.J. Eppler \& M. Aeschimann, Envisioning Risk: A Systematic Framework for Risk Visualization in Risk Management and Communication (Univ. of Lugano (USI), Lugano, Switzerland, ICA Working Paper No. 5, 2008), available at http://www.knowledgecommunication.org/pdf/envisioning-risk.pdf.; Martin J. Eppler, et al., Seven Types of Visual Ambiguity: On the Merits and Risks of Multiple Interpretations of Collaborative Visualizations, IEEE COMPUTER SOCIETY, IV 'O8 PROCEEDINGS OF THE 12TH INTERNATIONAL CONFERENCE INFORMATION VISUALISATION 391 (2008).
} 
These new web technologies seek to remove some of the obstacles facing the use of the Web in the context of deliberative democratic processes-in particular the problems of e-literacy, 54 computer anxiety, 55 and information overload ${ }^{6}$-by developing user-friendly interfaces and by reducing the cognitive effort associated with political engagement (e.g., by reducing search and processing costs in datasaturated environments).

The second challenge, which calls for sociological innovation, questions the capacity of Web-mediated human interaction to generate the kind of vitality that emerges in real-life social interactions and is critical to coping with the problems of attention and motivational scarcity. More concretely, the challenge in this context is to find ways by which online processes of democratic engagement can be linked with offline processes. Primo Levi referred to that enigmatic quality of face-to-face group interaction in one of his works when describing his experience of working in a laboratory as a student:

I remained friends with all my laboratory colleagues. It was the team work .... Making mistakes together is a fundamental experience. One participated fully in the mutual victories and defeats. Qualitative analysis, for example, in which they gave you a bit of powder and you were supposed to tell what was in it: not to realize there was bismuth or to find chrome that wasn't there

\footnotetext{
53 Roman Efremov, et al., A Framework for Participatory Decision Support Using Pareto Frontier Visualization, Goal Identification Arbitration, 199 EUROPEAN JOURNAL OF OPERATIONAL RESEARCH 459 (2009).

54 See Eszter Hargittai, Digital Na(t)ives? Variation in Internet Skills and Uses Among Members of the "Net Generation" 80 SOCIOLOGICAL INQUIRY 92 (2010).

55 Computer anxiety refers to the anxiety experienced by users who have to cope with unfamiliar or cognitively complex technology; See Benjamin R. Cowan \& Mervyn A. Jack, Exploring the Wiki User Experience: The Effects of Training Spaces on Novice User Usability and Anxiety Towards Wiki Editing, 23 INTERACTING WITH COMPUTERS 117 (2011); John J. Beckers, et al., Computer Anxiety: "Trait" or "State"?, 23 COMPUTERS IN HUMAN BEHAVIOR 2851 (2007).

${ }^{56}$ Kenneth E. Himma, The Concept of Information Overload: A Preliminary Step in Understanding the Nature of a Harmful Information-Related Condition, 9 ETHICS AND INFORMATION TECHNOLOGY 259 (2007); DAVID LEVY, Information Overload, in THE HANDBOOK OF INFORMATION AND COMPUTER ETHICS 497 (K. E. Himma \& H. Tavani eds., 2008).
} 
were adventures. We gave each other advice, we sympathized with each other. It was also a school of patience, of objectivity, of ingenuity, because the methods they suggested to you to perform an analysis could be improved: it was up to you to take a step forward on your own, to simplify. ${ }^{57}$

Primo Levi suggests that the heightened hopes directed to the Web may be problematic because they overestimate the capacity of the Web to sustain and recreate the social dynamic of offline democratic action, especially on highly structured and coordinated platforms. One of the paradoxes of e-democracy is that Web-based democratization seems to work best when it draws on spontaneous and non-hierarchical social processes, in which social and technological entrepreneurs play a crucial role. $5^{8}$ Once the project is institutionalized in a centrally coordinated and structured framework that seeks to generate a more systematic deliberation and consultation process, it seems much more difficult to create the kind of motivation and enthusiasm that are found in the non-coordinated, civic projects.

Overall, these dual challenges suggest that the exploration of the potential effect of ICTs on democratic processes should be guided by a non-deterministic and nuanced approach that pays closer attention to both the micro-details of the technological design and user-interface, 59 and to the social dynamic in which e-democratic processes are embedded. 60

\section{THE CANADIAN E-DEMOCRACY EXPERIENCE: “CONSULTING WITH CANADIANS" AND THE CASE OF TRANSLINK}

The tension between the administrative doctrine of "informed citizenship" and the literature on "low information rationality," which was evident also in the debate between Plato and Popper, generates a

\footnotetext{
57 Primo Levi \& Tuldio Regge, Dialogo 20 (Princeton University Press 1987).

${ }^{58} \mathrm{~A}$ recent great example of this spontaneous process was the use of the Web at the Tent Protest that took place in Israel in summer 2011.

59 Scott Wright\& John Street, Democracy, Deliberation and Design: The Case of Online Discussion Forums, 9 NEW MEDIA \& SOCIETY 849 (2007); Oren Perez, Electronic Democracy as a Multi-dimensional Praxis, 4 N.C. JOURNAL OF LAW \& TECHNOLOGY 275 (2003).

60 GRÖNLUND \& §̊STRÖM, supra note 13.
} 
deeply contested image of political life. E-democracy, both as a theoretical concept and a political-pragmatic program, is driven by the idea that the cleavage between these conflicting normative and sociological concepts can be minimized. But as a predominantly pragmatic project, the main challenge of e-democracy is practical. Can e-democracy mechanisms facilitate the emergence of political processes of engagement that approximate the democratic vision underlying the open government project? The goal of the following case studies is to develop a better understanding of the potential as well as the limits of e-democracy by exploring the technological and institutional structure of several e-democracy initiatives. I focus on the question of how various technological mechanisms are used to resolve the motivational challenge and to overcome the humantechnology barrier, highlighting also the role of technological intermediaries in these projects.

The first part of this Section focuses on the Canadian project "Consulting with Canadians," which represents some of the challenges faced by e-democracy projects managed by vast bureaucracies such as that of the Canadian Federal Government. The Consulting with Canadians portal provides Canadian citizens with single-window access to a list of consultations from selected government departments and agencies. ${ }^{61}$ My study focused on two Canadian Ministries: Health Canada and Foreign Affairs and International Trade Canada (DFAIT). The following analysis draws on interviews with officials from various agencies (conducted in September 2010) and on a study of their e-consultation portals.

A. E-Democracy at the Shadow of Big Bureaucracy: The Story of Two Agencies: Health Canada and Foreign Affairs and International Trade Canada

\section{Health Canada}

Health Canada (HC) ${ }^{62}$ is the federal department dealing with issues of public health. Among others, it is responsible for the

\footnotetext{
${ }^{61}$ See Consulting with Canadians, GOVERNMENT OF CANADA, http://consultingcanadians. gc.ca/cpcPubHome.jsp?lang=en (last accessed Oct. 12, 2011). The Canadian Government has recently established a new central "open government" portal (http://www.open.gc.ca/ index-eng.asp), which changes somewhat the structure of the consultation process. However the changes have been mostly minor; the following description thus remains relevant also to the new regime.

${ }^{62}$ Health Canada (Jan. 15, 2013), http://www.hc-sc.gc.ca/index-eng.php.
} 
administration of the Canada Health Act and regulates and approves the use of thousands of products, including consumer goods, foods, medical devices, natural health products, pesticides, pharmaceuticals, and toxic substances. ${ }^{63}$ Because the issues that fall under the responsibility of $\mathrm{HC}$ are highly relevant to the daily life of Canadian citizens, there is justification for involving the public in decisionmaking processes within HC.

As part of the commitment of the Canadian Federal Government to public consultation, HC operates its own online consultation portal, Public Involvement - HC. ${ }^{64}$ The website provides an up-to-date list of all open consultations and an archive of closed ones. The activities of $\mathrm{HC}$ regarding public involvement are guided by the Health Canada Policy Toolkit for Public Involvement in Decision Making (2000). The toolkit stipulates five principles that form the basis of $\mathrm{HC}$ public involvement strategy:

1. Health Canada is committed to public involvement which is integral to decision making and providing quality service.

2. Health Canada's public involvement activities improve knowledge and understanding of health issues through dialogue.

3. Health Canada is open to hearing the views of Canadians and providing timely feedback on the outcomes of dialogue.

4. Health Canada's public involvement activities reflect the diversity of Canadians' values and needs and are transparent, accessible and coordinated.

5. Health Canada provides guidance and ensures access to learning opportunities in support of employees' responsibility and accountability for planning,

\footnotetext{
${ }^{63}$ See the detailed description of HC at About Health Canada, HEALTH CANADA (Oct. 12, 2011), http://www.hc-sc.gc.ca/ahc-asc/activit/about-apropos/index-eng.php.

64 Public Involvement, HEALTH CANADA (July 17, 2012), http://www.hc-sc.gc.ca/ahcasc/public-consult/index-eng.php.
} 
designing, implementing and evaluating public involvement initiatives. ${ }^{65}$

The toolkit further defines citizen engagement as:

[T]he public's involvement in determining how a society steers itself, makes decisions on major public policy issues and delivers programs for the benefit of people. Citizen engagement is closely linked to the concept of social cohesion. Social cohesion refers to the building of shared values, reducing disparities in wealth and income, and enabling people to have a sense that they are engaged in a common enterprise and face shared challenges as members of a same community. ${ }^{66}$

The toolkit recommends that policy makers use a mix of instruments, ${ }^{67}$ considering e-democracy tools (computer assisted participation, interactive www.e-conferencing, online discussion groups/list servers) to be only some of the elements of a comprehensive suite of citizen engagement tools. ${ }^{68}$

The design of the $\mathrm{HC}$ online consultation portal is relatively simple and straightforward. Its consultation interface is based on a (new) Consultation Calendar, which lists all the open and closed consultations. ${ }^{69}$ It allows visitors to see at a glance what consultations are currently active and which ones will be coming up in the future. Furthermore, the system is color-coded by subject area for easy navigation, ${ }^{70}$ and the calendar includes search options by subject,

\footnotetext{
65 Health Canada, Health Canada Policy ToOlkit For Public Involvement in DECISION MAKING 11 (2000), http://www.hc-sc.gc.ca/ahc-asc/alt_formats/pacrbdgapcr/pdf/public-consult/2ooodecision-eng.pdf.

$66 I d$. at 16.

${ }^{67} I d$. at 20.

68 Id. at 24.

69 Consultation Calendar, HeALTH CANADA (Mar. 21, 2007), http://www.consultations.hcsc.gc.ca/public-consult/consultations/calendar-calendrier/index-eng.php. Images extracted on Feb. 9, 2012.

70 It distinguishes between 11 subject-areas, each designated by a different colour: About Health Canada, Consumer Product Safety, Diseases and Conditions, Drugs and Health
} 
region, or keywords. ${ }^{71}$ The calendar also allows visitors to toggle forward or backward between the months and it includes direct links to the webpages of the consultations.

For example, in July 2011, one of the open consultations dealt with "Proposed Improvements to Health Canada's Marihuana Medical Access Program." 72 The consultation webpage ${ }^{73}$ provided a detailed description of the suggested revisions to the program and invited those interested in providing comments to do so by email. $74 \mathrm{HC}$ stated that it is "committed to reviewing and considering all comments received" by the due date.

Products, Emergencies and Disasters, Environmental and Workplace Health, First Nations and Inuit Health, Food and Nutrition, Health Care System, Healthy Living, Science and Research.

${ }_{71}$ The calendar includes two available viewing formats, a compressed view which displays only a few consultations allowing visitors to see the entire month in a more calendar looking format and an expanded view which allows visitors to see all the consultations going on throughout the month.

72 The consultation opened on June 17, 2011 and was closed on July 31, 2011. The final report has not been published yet (as of 9 February 2012).

73 The main page was http://www.hc-sc.gc.ca/dhp-mps/consultation/marihuana/_2011/ program/consult-eng.php. The Calendar refers to a shorter version that usually refers visitors to the main consultation page (although not in this case for some reason) see: http://www.consultations.hc-sc.gc.ca/public-consult/consultations/calendar-calendrier/ consultation_e.php?id=614.

74 The end-date for this consultation was July 31, 2011. A dedicated email address was opened for this purpose: consultations-marihuana@hc-sc.gc.ca. 

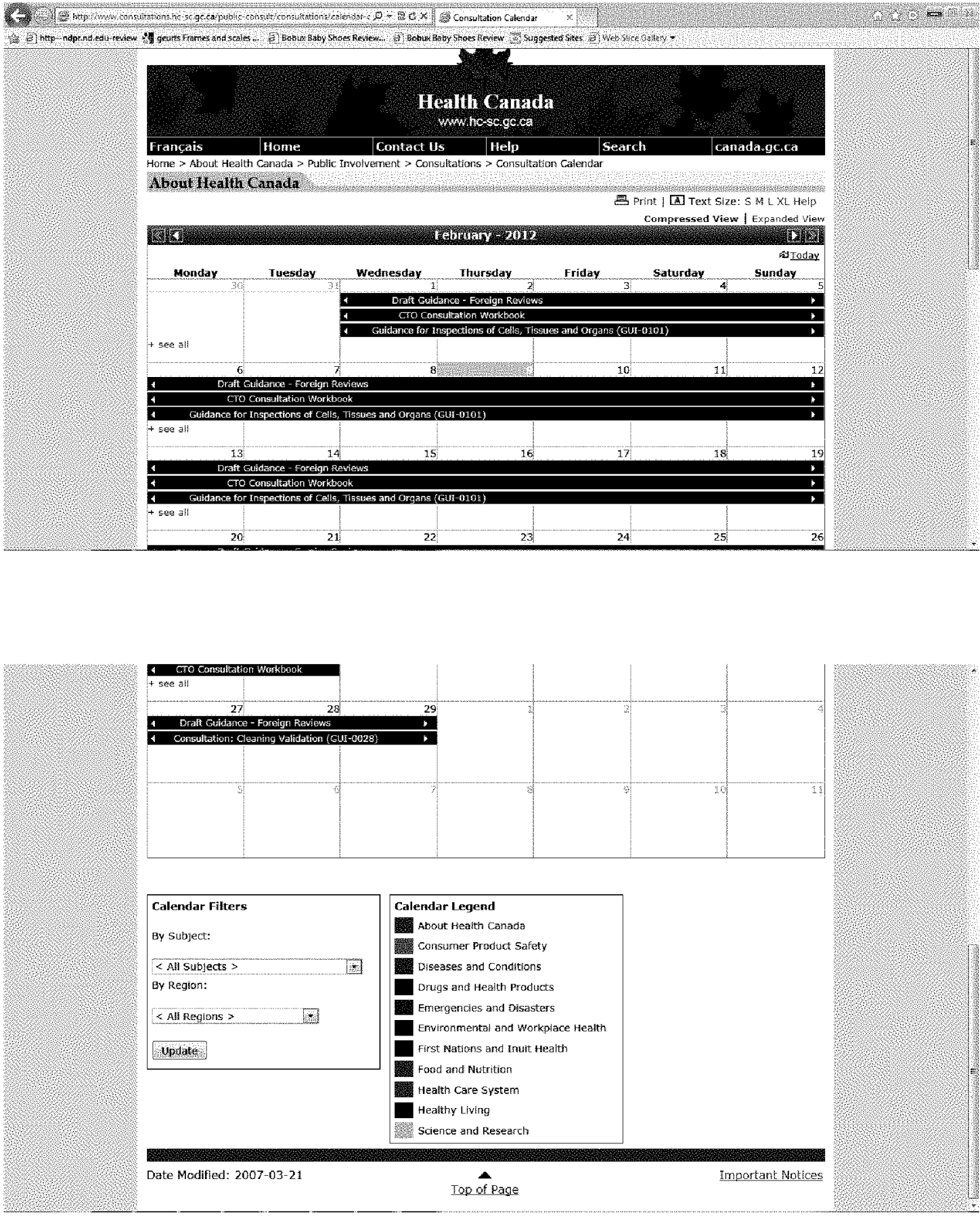
Although the calendar tool is innovative and enables visitors to navigate easily between the consultations opportunities, the vision of e-democracy offered by $\mathrm{HC}$ is relatively limited in that it is based primarily on the submission of comments by email. The HC portal does not provide opportunities for online dialogue or interaction. There is also no systematic disclosure of the comments received by the public and of the agency's reaction to them. Thus, in the consultation on "Proposed Improvements to Health Canada's Marihuana Medical Access Program," a hot topic that was surely a subject of interest within Canadian civic society, visitors could not see the comments made by other people during the online consultation. ${ }^{75}$

As part of this study I met with Marc-André Roy, Manager of the Strategic Advice and Coordination Unit, Consultations and Outreach Division, Public Affairs, Consultations and Communications Branch ("PACCB"), HC. ${ }^{76}$ According to the data he provided, between April 1, 2006 and September 30, $2010 \mathrm{HC}$ was involved in 357 departmental public and stakeholder consultation activities, attesting to an intensive consultation effort. ${ }^{77}$ The first point he made concerned the technical and human infrastructure supporting the $\mathrm{HC}$ online consultations effort. This infrastructure suffers from several flaws that impede extensive use of the participatory opportunities it provides. First, the search engine supporting the $\mathrm{HC}$ consultation website was not adequate, making it difficult to collect information..$^{78}$ Second, a critical component of the consultation project was a Stakeholder Information Management system, which included at the time 14,00o names. It was mainly used for outreach purposes (e.g., sending invitations to relevant stakeholders to take part in specific consultations). This data was highly dynamic and maintaining it up-to-date was costly.

\footnotetext{
$75 \mathrm{~A}$ good example for such ex-post disclosure is the consultation on Breast Implants, which took place between July 5, 2005 and Oct. 5, 2005. The consultation webpage (which is no longer available) included the inputs received by the public as well as the final expert advisory report.

${ }^{76}$ The meeting took place at HC offices in Ottawa on Sep. 17, 2011.

77 The full list is on record with the author. It includes both very technical consultations, which are directed to a smaller professional audience and in which participation rates tend to be rather small, as well as consultations that have broader public appeal. Compare for example the consultation on Boscalid, Proposed Maximum Residue Limit PMRL2010-37 (opened on June 25, 2010) to the consultation on Proposed changes to the Cosmetic Ingredient Hotlist (opened on Aug. 16, 2010). It should also be noted that the majority of these consultation are mandatory "regulatory consultation".

${ }^{78}$ This was ultimately improved through the calendar mechanism described above.
} 
However, only one person was responsible for maintaining the system.

Concerning the profile of the participants, Roy noted that they were predominantly experts: representatives of industrial firms, NGOs, members of professional associations such as the Canadian Medical Association, academics or former employees. Broader participation from the civic society was rare and limited to issues with strong public visibility (such as the consultation on breast implants).

With respect to the question of the barriers to broad participation, he emphasized the issues of complexity and informational overload. First, people did not have sufficient knowledge of the online consultation opportunities (despite the clear Web-posting); therefore, there was little public awareness of the project. It was also difficult to find related information on the Web. He noted that, although the information is posted on the website, citizens need to visit the website continually to look for updates and information on new consultations. There is no option at present to subscribe to a newsletter or an alerttype widget that would inform citizens that a new consultation has been posted. Finally, he found that there was broad cynicism about online consultation and its ability to influence policy making despite the clear government commitment to that effect on the $\mathrm{HC}$ portal.79 Many people simply bypass the agency, writing directly to members of parliament or ministers.

Generally he was skeptical of the capacity of Web consultation to produce consensual decisions. The greatest challenge posed by e-mail consultation is that participants have no opportunity to see the opposing views. This makes it difficult for government to find a middle ground, a "solution" that citizens holding different views could live with, and for participants to understand the decision eventually reached by the government. E-mail consultation tends to produce polarizing views. By contrast, face-to-face meeting causes people to reflect on what other people say.

Roy noted that there are various reasons why $\mathrm{HC}$ is not fully engaged in online dialogues or interactions. First, the fact that Canada is a bilingual country makes it difficult to moderate and hold discussions in two languages. Second, previous experiences and some studies showed that online dialogue such as forums do not produce indepth comments from participants. In this "Twitter / 140 character responses era" people tend to send only brief comments. While HC does receive quality comments by e-mail, drawing on the experiences

79 See Health Canada Policy ToOlkit for Public Involvement in Decision Making, supra note 65 , at 7 . 
in other departments with social media-type consultation made him cautious of the prospects of achieving high quality online discussion. Third, managing these processes and moderating comments one-byone is resource-intensive. $\mathrm{HC}$ does not have the in-house expertise to create those forums, and would need to contract them out, which may cost several thousands of dollars. Cost and efficiency are certainly issues for the Ministry. He also explained why HC does not make the comments available to the public. The agency cannot force people to identify themselves when they participate in a consultation (most of them do so, however, voluntarily). This issue has been discussed several times with legal services.

He emphasized several points about how the system may be improved. ${ }^{80}$ First, the information must be more accessible, and people should be able to obtain it without difficulty. Second, it is important to provide participants with follow-up reports, explaining the government reaction to the comments received. At times, some of $\mathrm{HC}$ branches are consulting for the sake of consulting (as when they are not prepared to change anything to the proposed policy or process). Third, it was important to secure the support of the "bosses." Finally, consistency is critical. HC is currently inconsistent in the way in which it conducts consultations, especially when it comes to deciding on what and when $\mathrm{HC}$ will be consulting. There is currently no prioritization of files, and each branch proceeds with its own project. He noted further that creating clear accountability lines is a key success factor in improving consistency.

\section{Foreign Affairs and International Trade Canada}

Foreign Affairs and International Trade Canada (DFAIT) engages Canadians through a variety of formal consultations on its policies, programs, and services. ${ }^{81}$ Most of the consultations deal with bilateral and regional initiatives, several of them with environmental assessments (EA) of trade negotiations. ${ }^{82}$ This practice began in early

\footnotetext{
${ }^{80} \mathrm{He}$ also noted that PACCB currently leads an initiative aimed at improving stakeholder and citizen engagement at $\mathrm{HC}$.

${ }^{81} \mathrm{~A}$ complete list of active and close consultations is available at http://international.gc.ca/ trade-agreements-accords-commerciaux/agr-acc/consultations.aspx?lang=eng\&view=d; http://www.international.gc.ca/consultations/index.aspx (last visited Jan. 25, 2013).

82 See, e.g., Initial Environmental Assessment of the Canada-Panama Free Trade Agreement (FTA), Foreign AfFAIRS AND InTERNATIONAL TRADE CANADA (Jan. 23, 2012), http://www.international.gc.ca/trade-agreements-accords-commerciaux/agr-acc/ panama/initialEA-panama-EEinitiale.aspx?lang=eng\&view=d.
} 
1999 as part of a commitment to assess the domestic environmental implications of a new round of trade negotiations at the World Trade Organization. It was subsequently broadened to apply to bilateral, regional, and multilateral negotiations. ${ }^{83}$ The framework has two key objectives. First, it provides a means to integrate environmental concerns into the negotiating process. ${ }^{84}$ Second, it seeks to provide a framework through which Canadian citizens can "have a say in the development of Canada's environmental policy and trade agenda," reflecting a more general commitment to incorporate public input into the environmental assessments of trade negotiations. ${ }^{85}$ Other consultations in this category involve the negotiation of new free trade agreements (FTA) ${ }^{86}$ and other economic agreements. ${ }^{87}$

The design of the DFAIT consultation portal is simple and it includes a list of all active and close consultations. ${ }^{88}$ Interested individuals are expected to send their contributions by e-mail, fax, or standard mail. 89 The portal does not offer tools for interactive dialogue. Comments received are not disclosed, and there is also no systematic attempt to summarize the government's response to these

\footnotetext{
83 FOREIGN AFFAIRS AND INTERNATIONAL TRADE CANADA, FRAMEWORK FOR CONDUCTING ENVIRONMENTAL ASSESSMENTS OF TRADE NEgOTIATIONS (Feb. 2001), available at http:// publications.gc.ca/collections/Collection/E2-213-2001E.pdf.

84 Id. at 16.

85 Id.; See also Trade Negotiations and Agreements, FOREIGN AFFAIRS AND INTERNATIONAL TRADE CANADA, http://www.international.gc.ca/trade-agreements-accords-commerciaux/ env/env-ea.aspx?lang=en (last accessed Nov. 30, 2012).

${ }^{86}$ E.g., consultation on a possible FTA between Canada and Ukraine.

87 E.g., consultation on Possible Negotiations for a Comprehensive Economic Partnership Agreement with Japan.

88 Consultations, Foreign AFFAIRS AND InTERnATIONAL TRADE CANADA, http:// international.gc.ca/trade-agreements-accords-commerciaux/agr-acc/consultations. aspx?view=d (last accessed Jan. 24, 2013).

89 There is a central email address managed by the consultation unit: consultations@international.gc.ca.
} 
comments. $9^{\circ}$ On rare occasions, DFAIT uses structured questionnaires to elicit public responses, mainly targeting business players..$^{1}$

\section{The DFAIT Portal92}

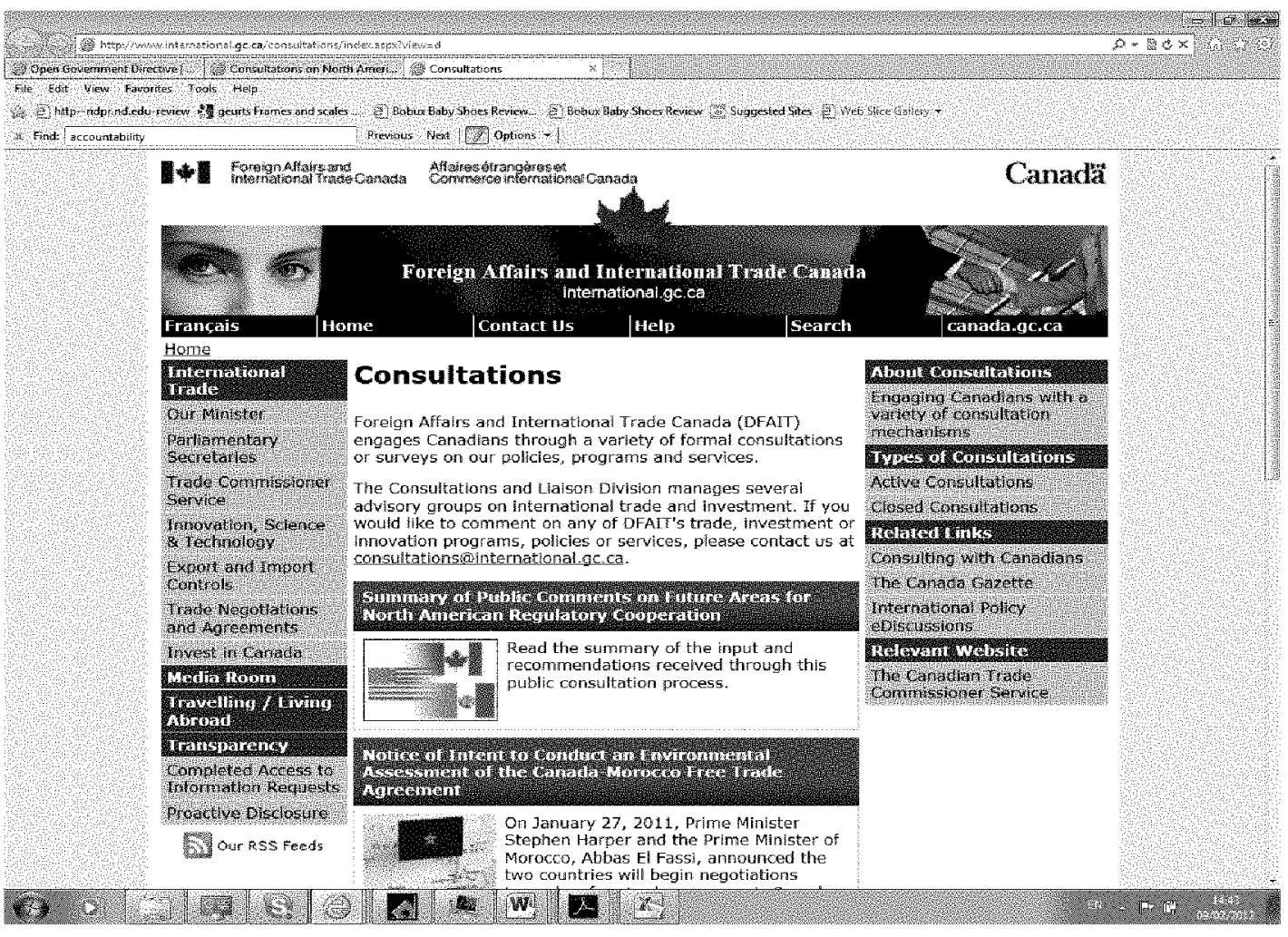

${ }^{\circ}$ There are some rare exceptions. See, e.g., Summary of Discussions - ACTA Roundtable Consultation, Apr. 6, 2009, http://www.international.gc.ca/trade-agreements-accordscommerciaux/fo/discussion_summary-resume.aspx?lang=eng\&view=d (last accessed Mar. 7, 2013).

91 This was done, for example, in the context of Consultation on Services Trade Negotiations, Consultation to Assess Canadian Intellectual Property Interests in Selected Markets and Consultation on OECD Guidelines for Multinational Enterprises Review: Call for Stakeholder Input. OECD Guidelines for Multinational Enterprises Review: Call for Stakeholder Input, FOREIGN AFFAIRS AND INTERNATIONAL TRADE CANADA, http:// www.international.gc.ca/trade-agreements-accords-commerciaux/agr-acc/oecd-consultocde.aspx?lang=eng\&view=d (last accessed Nov. 27, 2012).

92 FOREIGN AFFAIRS AND INTERNATIONAL TRADE CANADA, http://www.international.gc.ca/ consultations/index.aspx/Viewed (last viewed Apr. 15, 2013). 
I met with an official of the Consultations and Liaison Division (CLD), DFAIT on September 8, 2010. The meeting exposed the difficulties that the establishment of online consultation projects faces in large and complex bureaucratic environments such as DFAIT. The official noted, first, that CLD operates only as a coordination hub responsible for managing the mailbox, forwarding the input received to the relevant units responsible for the specific consultations. 93 One of the difficulties they were facing was that many of the issues discussed in the consultations fell under the jurisdiction of the Trade, Policy and Negotiation Branch, whereas CLD belongs to the International Business Development, Investment and Innovation Branch, which resulted in a conflict in the hierarchy. He noted that one of the greatest challenges of CLD was building and maintaining a central stakeholder database (a point also made by the $\mathrm{HC}$ official). Such a database would be an important tool for keeping in touch with the stakeholder community and alerting interested citizens about open consultations, but was costly to manage because of frequent changes in its composition which required constant monitoring. CLD did not have the workforce or budget to accomplish this. 94

In response to a question about information overload, he noted that it would be a problem for government as well, giving as an example the managing of junk-mail, spam, and phishing. Regarding the profile of participants in the consultations he noted that they tend to be small and medium businesses, some academics, and specialinterest groups. Large corporations often use other means to deliver their views, communicating directly with ministers or with negotiators. He also noted that the substantive quality of e-mails tended to be rather poor, and emphasized the need to improve matters. Currently the e-consultation portal has done little more than putting the old print-based notification system (the Canada Gazette system) online. There was no attempt to meet the challenges of the new medium.

\footnotetext{
93 He noted in that context that a large part of his unit workload is devoted to coping with junk mail (filtering, etc.). He also noted that CLD was at one time responsible for managing DFAIT consultations published on Canada Gazette, but this was now done directly by the units undertaking the consultation.

94 The email box is maintained by a $25 \%$ position.
} 


\section{B. E-Democracy as Social Engineering: Bringing the Offline and Online Worlds Together in TransLink's Consultation Strategy}

TransLink is the South Coast British Columbia Transportation Authority. It operates under the South Coast British Columbia Transportation Authority Act ("the Transportation Act"). 95 TransLink is responsible both for the operation of various transportation services, from trains to buses, and for the development of related infrastructure projects (such as railways, roads, and bridges). The scale of its responsibilities and the possible social and environmental effects of its actions are enormous. As a hybrid body, TransLink represents a different institutional environment than the giant bureaucracies of the Canadian Federal Government. This is reflected not only in a different institutional culture but also in the greater ability of TransLink to mobilize the resources needed to support its consultation activities. This financial capacity, coupled with a strategic commitment to the vision of civic engagement, has generated a highly dynamic participatory culture that delivered better results both in the scale and in the quality of the participatory process.

TransLink has made a far-reaching commitment to involve the public in its decision-making processes. This is reflected in an internal consultation code entitled, "Principles for Public Consultation and Community Engagement" which consists of nine principles:

1. Integrate public consultation into all applicable aspects of TransLink's business.

2. Consider both local and regional perspectives.

3. Work with municipal partners.

4. Clearly define the parameters of the consultations.

5. Consult in advance of key decisions.

6. Be inclusive and accessible by offering a variety of opportunities for input.

95 About Us, TRANS LINK, http://www.translink.ca/en/About-Us.aspx (last visited Jan. 25, 2013). 
7. Ensure participants have the opportunity to provide informed input.

8. Consider public input as advice.

9. Inform participants about the results of the consultation process. ${ }^{96}$

The Code draws on the narrative of the "informed citizen." It requires TransLink to establish the necessary conditions for "informed input," 97 to consider "public input as advice," and to "inform participants about the results of the consultation process." 98

TransLink offers the public an opportunity to become involved in three types of consultation schemes: Plans, Projects, and Studies.99 The TransLink approach to consultation emphasizes offering a mixture of online and offline consultation opportunities. Furthermore, in its online consultation, it uses a variety of tools that simplify and broaden participation. The tools include stakeholder meetings, Transportation Fairs, online e-consultations through TransLink's website, and online surveys using a unique online advisory panel.

To get a sense of TransLink's consultation strategy I want to consider a concrete example in some detail. This analysis demonstrates TransLink's commitment to a multifaceted consultation strategy and its capacity to mobilize the necessary funds to implement this strategy. The 2012 Transportation and Financial Supplemental Plan entitled, "Moving Forward: Improving Metro Vancouver's

${ }_{96}^{6}$ Principles For Public Consultation, TRANSLINK, http://www.translink.ca/en/AboutUs/Corporate-Overview/Principles-for-Public-Consultation.aspx (last visited Jan. 25, 2013). The principles are further elaborated in the website.

97 The detailed elaboration of principle seven emphasizes TransLink's commitment to the model of "informed citizenship": "Public consultation requires informed participants. TransLink will ensure sufficiently comprehensive and accurate information in a variety of formats is available to participants in a timely manner, and that opportunities for interaction with TransLink representatives are provided, so questions can be answered as part of the information-sharing process." Id.

98 TransLink emphasizes that it will take seriously the public comments: "TransLink will report to the public on the results of its consultation processes in a variety of locations and formats, and will demonstrate how public input has been used in its decision-making processes." Id. This is an elaboration to principle nine.

99 Be Part of the Plan, TRANSLink, http://www.translink.ca/en/plans-and-projects/bepart-of-the-plan.aspx (last visited Jan. 25, 2013). 
Transportation Network," was the subject of a series of consultation phases. ${ }^{100}$ The consultation was considered to be important because the plan involved a massive and costly network expansion that would have a significant influence on the life of the region's citizens. The first consultation phase took place at the end of 2010, the second in July of 2011. ${ }^{101}$ It included several stakeholder meetings, three Transportation Fairs, online e-consultations through TransLink's website, and a survey of the TransLink Listens online advisory panel. Approximately 1,00o people attended the Fairs in Vancouver, Coquitlam, and Surrey; 455 of them completed a seven-page questionnaire. ${ }^{102} \mathrm{~A}$ concurrent online public e-consultation between October 15-28, 2010 involved two online surveys: 316 people $(1,260$ webpage views) completed a nine-item questionnaire for the 2011 Supplemental Plan, and 205 people (611 webpage views) completed a three-item questionnaire for the Service Optimization Initiative. On October 15, 2010, an invitation to the 2011 Supplemental Plan survey was sent to all TransLink Listens panel members $(5,969)$ with the completion deadline of October 21, 2010. A total of 2,233 panelists completed the survey. This multifaceted approach characterizes other consultation efforts related to TransLink projects and studies. ${ }^{103}$ One of the most innovative features of the TransLink consultation framework is TransLink's OnLine Advisory Panel. ${ }^{104}$ This tool allows TransLink to generate a substantial number of civic reactions to various projects, although at

\footnotetext{
100 MOVING FORWARD: IMPROVING METRO VANCOUVER'S TRANSPORTATION NETWORK, http://www.translink.ca/ /media/Documents/plans_and_projects/10_year_plan/ 2012_Plans/2012\%20Moving\%20Forward\%20Supplemental\%20Plan\%20Highlights.ashx (last accessed Mar. 7, 2013); see also TRANSLINK, MOVING FORWARD: IMPROVING METRO VANCOUVER'S TRANSPORTATION NETWORK, 2012 SUPPLEMENTAL PLAN AND OUTLOOK (Sept. 23, 2011), http://www.translink.ca/ /media/documents/plans_and_projects/10_year_ plan/2012_plans/2012_supplemental_plan_moving_forward.ashx.

${ }^{101}$ The first phase is described in detail in a summary document prepared by TransLink. Report from Robert Paddon, Vice President, Corporate and Public Affairs, to the TransLink Board of Directors, Consultation Plan for the 2011 Supplemental Plan and Principles for Service Optimization (Nov. 5, 2010), http://www.translink.ca/ /media/Documents/ plans_and_projects/public_consultation/2011_supplemental/questionnaire_and_reports /Final\%20Consultation\%20Summary\%2oReport.ashx.

$102 I d$. at 2.

${ }_{103}$ See Be Part of the Plan, TRANSLINK, http://www.translink.ca/en/plans-and-projects/ be-part-of-the-plan.aspx (last visited Jan. 25, 2013).

104 See TransLink Listens Online Advisory Panel, TRANSLINK, http://www.translink.ca/ en/Customer-Service/Translink-Listens-Online-Panel.aspx (last visited Jan. 25, 2013).
} 
the cost of channeling these reactions through structured and relatively simple surveys. Citizens seeking to join the Advisory Panel are asked to complete a brief profile questionnaire. ${ }^{105}$ By opting in to the On-Line Advisory Panel, participants enter into a drawing to win one of two prizes of $\$ 500$ each. ${ }^{106}$ Every month, TransLink sends surveys to Panel members, which take five to ten minutes to complete. ${ }^{107}$ Because the Advisory Panel is used mainly for polls and does not allow for "open" comments or for dialogue, its deliberative potential is rather limited. Nevertheless, it has the potential benefit of distinguishing between different classes of participants according to their willingness to engage in a cognitive effort in the context of participatory exercises. To better understand the corporate culture that drives TransLink efforts in the area of consultation, I met with three officials from TransLink. ${ }^{108}$ Regarding TransLink's communicative efforts, they emphasized that outreach has become a substantial element of the TransLink institutional culture, with strong management and organizational support. They also emphasized TransLink willingness to invest substantial funds to develop and implement consultation projects. For example, TransLink invested one million Canadian dollars in promoting the consultation

105 TransLink Listens, TRANSLink, https://join.translinklistens.ca/S.aspx?s=2\&r= FrwxLBascEKXAQSNOwNHMQ\&a=8\&fromdetect=1 (last visited Jan. 25, 2013).

${ }^{106}$ For the rules of the contest, see TransLink Listens Panel, Contest Conditions for Registration, Recruit Draw, TRANSLINK, https:// www.translinklistens.ca/MediaServer/ 2/documents/Contest\%20Rules_TransLink\%20Listens\%20Recruit_Mar-Sept2011.pdf (last visited Jan. 25, 2013).

107 It also promises to send each participant the results of each survey in which she takes part. The Online Advisory Panel mechanism raises obvious questions of privacy. TransLink states in that context that " $[w]$ e will carefully protect your personal information and ensure that your e-mail address is used solely for the online advisory panel, in accordance with privacy legislation governing TransLink. Your opinions will be held in complete confidence." TransLink Listens Online Advisory Panel, TransLink, http:// www.translink.ca/en/Customer-Service/Translink-Listens-Online-Panel.aspx (last visited Jan. 25, 2013).

108 Community Relations Coordinator, Online Communications Advisor and external consultant (from Common Junction Strategies Inc.). The meeting took place on Sep. 28, 2010 at TransLink main offices. I also draw on a presentation (Consultation 2.0, Leveraging Online), which describes the 10-year plan consultation process, and was provided to me by the external consultant. 
surrounding the 10-year plan. ${ }^{109}$ Another point they emphasized concerned the need to use a blended approach in designing consultation exercises, both in the sense of mixing offline and online mechanisms and in the sense of using a variety of online tools (blogs, Web-portals, Facebook, Twitter). They also emphasized the need to adopt a non-naive approach to online consultation, which takes into account the obstacles to online participation. Building an online community that can provide peer support and recognition is critical for the success of such exercises. One way to achieve this goal, which was used in the 10-year plan consultation process, was to design the consultation process in two phases; Phase One was dedicated to building awareness of the campaign, and Phase Two consisted of the consultation itself. They also noted in this context the importance of linking the consultation process with dominant social media tools such as Facebook and Twitter. Finally, the officials noted the importance of designing the consultation webpage in a simple and user-friendly way. Giving participants too many options could prove counter-productive. In the 10-year plan consultation process they used a game-like design, which enabled participants to voice their priorities on potential investment categories in a simple fashion. ${ }^{110}$

\section{THE LIMITS OF TECHNOLOGICAL INNOVATION: ACCOUNTABILITY'S TRANSNATIONAL WIKI EXPERIMENT}

\section{A. Wikis as Deliberative Mechanisms: Theoretical Reflections and Predictions}

The idea of using Wikis as a medium for deliberative consultation has been proposed by several writers and practitioners of edemocracy. ${ }^{111}$ Beth Noveck used "Wiki-Government" as a general term

\footnotetext{
${ }^{109}$ See http://www.translink.ca/en/Plans-and-Projects/10-Year-Plan.aspx (last accessed Mar. 7, 2013). In part this was also related to TransLink attempt to raise public funding for its future projects and the need to demonstrate public support.

110 For a more detailed discussion see Consultation 2.o, Leveraging Online (on file with the author).

${ }^{111}$ Nathaniel J. Klemp \& Andrew T. Forcehimes, From Town-Halls to Wikis: Exploring Wikipedia's Implications for Deliberative Democracy, 6 JOURNAL OF PUBLIC DELIBERATION 2 (2010); Olivier Glassey, A Survey on Participation at Geneva's Constituent Assembly, in ELECTRONIC PARTICIPATION, SECOND IFIP WG 8.5 INTERNATIONAL CONFERENCE, EPART 2010, LAUSANNE, SWITZERLAND, AUGUST/SEPTEMBER 2010 PROCEEDINGS 151 (Efthimios Tambouris, et al. eds., 2010); Rowena Cullen \& Laura
} 
to describe the concept of collaborative democracy, which for her realizes the ideal of legitimate governance in the twenty-first century. ${ }^{112}$ Some authors argue that the social interaction facilitated by Wiki platforms such as Wikipedia can realize the epistemic and procedural aspirations of deliberative democracy. ${ }^{113}$

The Wiki platform allows multiple users to jointly create one hypertext, providing a mechanism for collaborative learning and knowledge production. Wikis also constitute a forum in which visitors can engage in dialogue and share information, facilitating a debatebased learning experience. ${ }^{114}$ As demonstrated by Wikipedia, Wiki processes can be highly flexible and are capable of responding quickly to social events. ${ }^{115}$ The Wiki platform fulfills several functions that contribute to the rationality and reflexivity of the deliberative process. First, because the Wiki platform requires participants to follow a given protocol in making their contributions, it can be used to impose certain rules on the discursive contributions of the participants regarding both their form and substance (justification). ${ }^{116}$ Wiki platforms, therefore, provide a structured space for the dialogue. In Wikipedia, there is a structured decision-making process that even allows for the deletion of articles that do not meet the required

Sommer, Participation 2.o: A Case Study of e-Participation within the New Zealand Government, 42ND HAWAII INTERNATIONAL CONFERENCE ON SYSTEM SCIENCES (2009).

112 Beth Simone Noveck, Wiki Government: How Technology Can MaKe Government BETTER, DEMOCRACY STRONGER, AND CITIZENS MORE POWERFUL xiv (Brookings Institution Press 2009).

113 Klemp \& Forcehimes, supra note 111.

114 Ulrike Cress \& Joachim Kimmerle, A Systemic and Cognitive View on Collaborative Knowledge Building with Wikis, 3 INT'L J. OF COMPUTER-SUPPORTED COLLABORATIVE LEARNING 105, 107 (2008); Kevin R. Parker \& Joseph T. Chao, Wiki as a Teaching Tool, 3 INTERDISC. J. OF KNOWLEDGE AND LEARNING OBJECTS 57, 58 (2007), available at http:// chep2012.wmwikis.net/file/view/Parker+\%26+Chao+2007+-+Wiki+as+a+Teaching+ Tool.pdf.

115 Andrew Lih, Wikipedia as Participatory Journalism: Reliable Sources? Metrics for Evaluating Collaborative Media as a News Resource, in PROCEEDINGS OF FIFTH INTERNATIONAL SYMPOSIUM ON ONLINE JOURNALISM, APR. 16-17, 2004, AUSTIN, TX 216 (Rehg, McBurney, and Parsons eds., 2005).

116 Such rules could be imposed either through the work of human moderators or through technological means, or through combination of the two. See, e.g., Wikipedia: Policies and Guidelines, WIKIPEDIA, http://en.wikipedia.org/wiki/Wikipedia:Policies_and_guidelines (last accessed Dec. 19, 2012). 
epistemic criteria. ${ }^{117}$ Second, Wikis enable participants to monitor the deliberative process as it unfolds, keeping track of the issues and arguments being raised. In this capacity the Wiki system plays a record-keeping role, providing a complete description of the deliberative process and assisting participants in overcoming the problem of information overload as they struggle to deal with the information generated through the deliberative process. ${ }^{118}$

There are nevertheless several reasons for skepticism about the capacity of Wikis to generate the kind of ideal democratic processes envisioned by the proponents of e-democracy. The first potential barrier is the high cognitive cost associated with organizing and updating content on Wikis. ${ }^{119}$ The Wiki interface is still unfamiliar to most Internet users, for whom e-mail and social media like Facebook and Twitter constitute a more natural route for Web-based interaction. These cognitive difficulties may be coupled by what the literature has termed Wiki or computer anxiety, referring to the anxiety experienced by users who have to cope with unfamiliar or cognitively complex technology. ${ }^{120}$ Wiki anxiety can also be associated with the unique social dynamic of the Wiki architecture, which subjects each contribution to peer evaluation. The fear from negative evaluation by peers may create additional barriers for individuals with

117 D. Taraborelli \& G. L. Ciampaglia, Beyond Notability. Collective Deliberation on Content Inclusion in Wikipedia, 2010 FOURTH IEEE INTERNATIONAL CONFERENCE ON SELFADAPTIVE AND SELF-ORGANIZING SYSTEMS WORKSHOP, at 122 (2010), available at http:// nitens.org/docs/qteso10.pdf; Wikipedia: Deletion Policy, Wikipedia, http://en. wikipedia.org/wiki/Wikipedia:Deletion_policy (last accessed Jan. 22, 2013).

118 Ideally, argumentation systems should allow participants, with respect to each issuethread, to keep track of the exchange of arguments and counter arguments, the reasons offered for each argument and the conclusions drawn. However, this is not one of the strongest points of the Wiki architecture, because, while possible, tracking the history of the conversation may be quite complex. See David Schuff, et al., Designing Systems that Support the Blogosphere for Deliberative Discourse, 2 AIS TRANSACTIONS ON HUMANCOMPUTER INTERACTION 95 (2010); Rob Ennals, et al., Highlighting Disputed Claims on

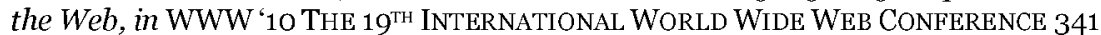
(2010), available at http://ennals.org/rob/archive/intel/pubs/disputefinder_www.pdf.

119 Changyan Chi, et al., IBM Research Division, Using Email to Facilitate Wiki-Based Coordinated, in CHI ' 11 PROCEEDINGS OF THE SIGCHI CONFERENCE ON HUMAN FACTORS IN COMPUTING SYSTEMS 3459, 3460 (2011), available at http://domino.research.ibm.com/ library/cyberdig.nsf/papers/C3E9008DD701F95E852577C4004F4121/\$File/rc25056.pdf; Nicholas Kong, et al., VisualWikiCurator: A Corporate Wiki Plugin, in CHI EA '11: CHI '11 EXTENDED ABSTRACTS ON HUMAN FACTORS IN COMPUTING SYSTEMS 1549 (2011).

120 Cowan \& Jack, supra note 55; Beckers, et al., supra note 55. 
a high level of social anxiety. ${ }^{121}$ Klemp and Forcehimes suggested that allowing participants to maintain anonymity could provide a solution to this anxiety, ${ }^{122}$ but this is only a partial solution, especially when the size of the group is small, first, because anonymity does not completely resolve the fear of negative peer evaluation (as the self remains fully conscious of its own identity); and second, because anonymity may bring about other negative effects, such as contributions that are epistemologically shallow or abusive, as the experience of talkbacks in online publications demonstrates. ${ }^{123}$

This discussion suggests that Wiki technology can facilitate deliberative processes that come close to our ideal democratic intuitions only when they are embedded in an environment of social and political cohesiveness, which can support such cognitively complex and emotionally intensive social interaction. Indeed, Klemp and Forcehimes argue that the architecture of anonymous online interactions that characterizes the Wikipedia model will not be able to cultivate the type of social capital and solidarity that is associated with real-world politics. ${ }^{124}$ This argument seems to expose a deeper problem, which has not been given sufficient attention by Klemp and Forcehimes: can Wiki structures facilitate online deliberative processes in the absence of an existing political bonding? Klemp and Forcehimes recognize these difficulties, noting that the procedural and epistemic virtues of Wikipedia tend to decline together with the size of the interactive community. ${ }^{125}$ Klemp and Forcehimes further raise the question of whether the Wikipedia model, which evolved as a collective epistemic-encyclopedic enterprise, is suitable for the political domain in which the conversation is not only about questions of fact but also about normative and ethical matters. They argue that when deliberations turn from the epistemic to the normative level,

\footnotetext{
121 Annette M. La Greca \& Nadja Lopez, Social Anxiety Among Adolescents: Linkages with Peer Relations and Friendships, 26 JOURNAL OF ABNORMAL CHILd PSYCHOLOGY 83 (1998); Cowan \& Jack, supra note 55.

122 Klemp \& Forcehimes, supra note 111, at 27.

123 Nicholas Diakopoulos \& Mor Naaman, Towards Quality Discourse in Online News Comments, in CSCW' 11 PROCEEDINGS OF THE ACM 2011 CONFERENCE ON COMPUTER SUPPORTED COOPERATIVE WORK 133 (2011); Neil J. Thurman, Forums for Citizen Journalists? Adoption of User Generated Content Initiatives by Online News Media, 10 NEW MEDIA \& SOCIETY 139 (2008).

124 Klemp \& Forcehimes, supra note 111, at 29.

125 Klemp \& Forcehimes, supra note 111, at 27.
} 
face-to-face deliberation may be better because it "enables participants not merely to exchange information but to transform their existing beliefs and values-to arrive at a more reflective set of beliefs through discussions with others." ${ }^{126}$ They conclude the argument by stating that the mode of interaction within Wikipedia may supplement face-to-face deliberation: "The Wikipedia model promotes inclusion and accuracy when used at a large scale, while the face-to-face model promotes solidarity and social capital and excels in conditions of localism." 127 One of the questions left unresolved in the Klemp and Forcehimes model is whether the different universes of the Wiki space and of face-to-face interaction can be brought together in a co-enhancing, synergetic way?

\section{B. AccountAbility's Transnational E-Democracy Project: Wikis in the Service of Transnational Democratization}

AccountAbility's transnational e-democracy project can shed light on some of the problems underlying the use of Wiki technology to foster online democratic engagement. AccountAbility is a transnational organization that develops global standards on corporate responsibility and sustainable development. ${ }^{128}$ The AA10oO series of standards, which was developed by the organization, includes three standards, one of which-the AA10oo Stakeholder Engagement Standard (AA100oSES) -was the subject of the consultation process studied in this article. Stakeholder engagement is defined as "the process used by an organization to engage relevant stakeholders for a clear purpose to achieve accepted outcomes" and as "a fundamental accountability mechanism, since it obliges an organization to involve stakeholders in identifying, understanding and responding to sustainability issues and concerns, and to report, explain and be answerable to stakeholders for decisions, actions and performance."129 AA10ooSES seeks to provide a basis for designing and implementing

\footnotetext{
126 Klemp \& Forcehimes, supra note 111, at 29.

${ }^{127}$ Klemp \& Forcehimes, supra note 111, at 2.

128 See ACCOUNTABILITY, http://www.accountability.org/standards/index.html (last visited Jan. 25, 2013).

129 ACCOUNTABILITY, AA1000 STAKEHOLDER ENGAGEMENT STANDARD 2011: FINAL EXPOSURE DRAFT 6 (2011), http://www.accountability.org/images/content/3/6/362/ AA100OSES\%202010\%2OPRINT.PDF.
} 
stakeholder engagement in a credible way. ${ }^{130}$ AccountAbility's standards are used by a broad spectrum of organizationsmultinational businesses, small and medium enterprises, governments and civil societies. ${ }^{131}$

Given the subject matter of AA1oooSES, it was particularly important for AccountAbility to revise the standard through a credible consultation process, which was based on two main deliberative mechanisms, including both Wiki ${ }^{132}$ and face-to-face consultation groups that met in different countries and discussed the draft standard in the first phase of the consultation process.

By drawing on a Wiki platform to facilitate the collaborative drafting process, AccountAbility sought to address two challenges: access and transparency. ${ }^{133}$ The deliberative process was not completely open and non-hierarchical. It was governed by the AccountAbility Stakeholder Engagement Technical Committee, which reviewed and revised the drafts after each consultation phase. The final draft was agreed by the Technical Committee and submitted to the AccountAbility Standards Board, which approved it for publication. ${ }^{134}$ The consultation process was conducted in three phases of public review of sixty to ninety days each, followed by a final thirty-day exposure period of the final draft, which took place between October 2009 and January 2011. ${ }^{135}$ This allowed the AccountAbility team and the technical committee to take stock of the comments received during each interval. This section offers an analysis of the Wiki facet of the consultation process undertaken by AccountAbility.

The present study draws on two main sources of data. First, I was given access to the Google statistics of the Wiki website. With my research team, I monitored the data related to the website during the

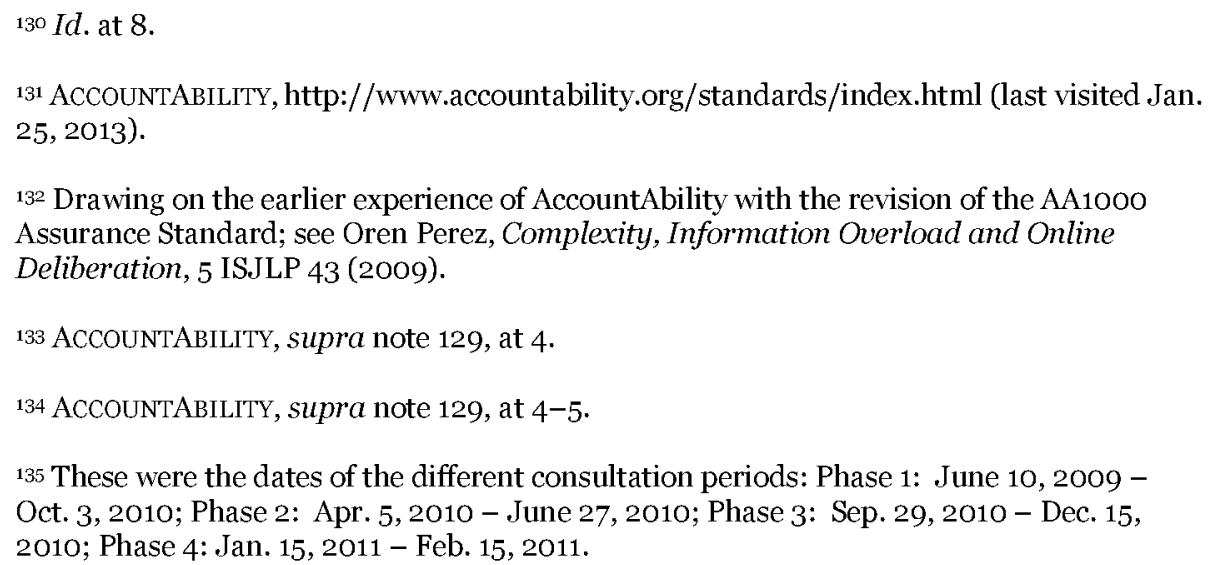


first phase of the consultation process. I focused on the first phase because this stage involved the face-to-face consultation meetings, and I wanted to explore the interaction between the two deliberative forums. Second, I conducted a survey of the participants in the Wiki consultation group, drawing on a list of names given to us by AccountAbility. This survey was supplemented by an interview with key people from AccountAbility.

\section{The Google Statistics Analysis of the Wiki Website}

\section{a. Method and Findings}

We analyzed the Google Analytics data set of the first phase of the consultation, from Oct. 6, 2010 to Mar. 10, 2010. ${ }^{136}$ We obtained data about daily visits distributed by the countries from which the visitors arrived. We found that there was an average of twenty-five to fortyfive daily visits to the site. The relatively higher volume of visits in November 2009 (forty-five) could be attributed to the large number of consultation group meetings conducted during that month (seven consultation groups out of a total of twenty). We also examined the geographical distribution of visitors and found that most visitors came from the UK (seventeen percent) (where the headquarters of AccountAbility are located), Europe (forty-two percent), and North America (thirteen percent). ${ }^{137}$

\footnotetext{
${ }_{136}$ We started monitoring the website before the formal opening of the consultation on Sep. 23,2009 . We wanted to focus on the interaction between the offline and online consultation. The discussion I had with AccountAbility team confirmed that the pattern we found, lack of external use of the Wiki itself, continued till the end of the consultation.

${ }^{137} 11 \%$ came from East, south and central Asia, $7 \%$ from South and Central America, 6\% from Australia and New Zealand and 3\% from Africa and the Middle East. Israel, Russia, and Turkey are included in the European category. The Asian category includes states from east-Asia such as Japan and China, as well as states from central- and south-Asia, such as Kazakhstan, India, and Pakistan. The Middle East category includes Iran and Arab states.
} 
Figure 1: Mean number of visits to the site per day, ordered by month ${ }^{138}$

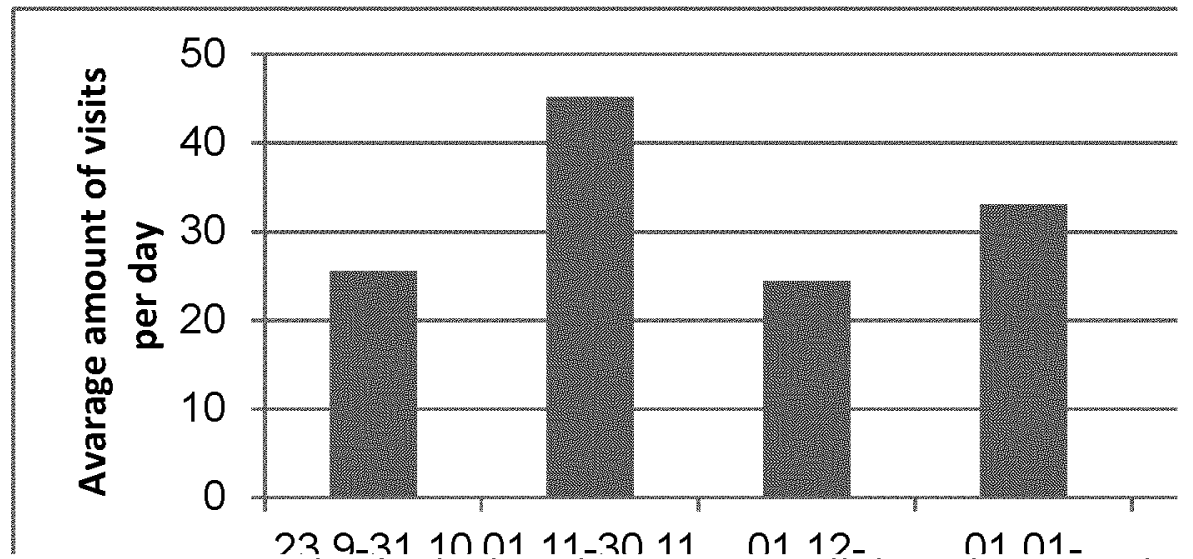

We next examined whether there was any linkage between the offline consultation workshops organized by AccountAbility and the Wiki process. AccountAbility organized a total of twenty consultation workshops, starting on Oct. 1, 2009, in South Africa and ending on Mar. 16, 2010 in Frankfurt. ${ }^{139}$ The workshops took place all over the globe, from Argentina to Israel, India, the UK, and Australia. The full list of meetings and their dates is included in Appendix $A$. We expected to find a positive correlation between dates close $^{140}$ to the meetings and the activity on the Wiki website. All the workshops produced written feedback that was based on a structured form prepared by AccountAbility. Most of the responses were detailed, with an average length of seven pages. We found that the mean number of visits for days in proximity to consultation group meetings was significantly higher than the mean number of visits on other days. ${ }^{141}$ This pattern is illustrated in the graph in Figure 2.

\footnotetext{
138 Including all days in proximity to workshops.

139 The workshop in Frankfurt was not included in the analysis, since it was conducted after the end of the first phase of the consultation process. We also excluded from the analysis an additional meeting in Budapest, because we could not verify its exact date.

140 We defined days to be in proximity to consultation group meeting in case the meeting was scheduled for that specific day or for the following two days.

141 The descriptive statistics for days in proximity to consultation group meetings and for days not in proximity to consultation group meetings, from Sep. 23, 2009 to Mar. 10, 2010, is reproduced in Appendix B.
} 
Figure 2: Total visits to the site for each date, from Sep. 23, 2009 to Mar. 7, 2010.

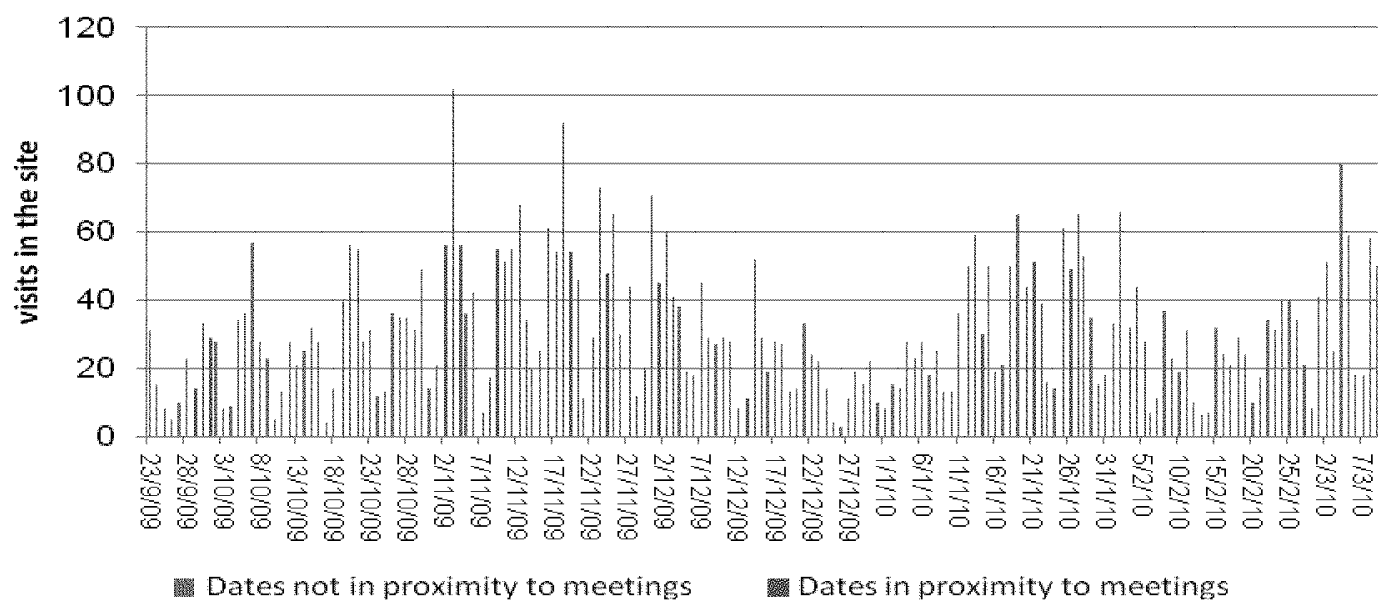

Another indication of the association between site visits and faceto-face consultations is that, in almost all countries (except for Hong Kong), the mean number of visits to the Wiki website was substantially higher on days close to the consultation meeting than on other days. Summing up the results for the seventeen countries that had a consultation meeting provides a good proxy for this finding: the mean number of visits on days close to meetings was $4.89(\mathrm{SD}=3.27)$, compared with $1.15(\mathrm{SD}=1.32)$ on other days. ${ }^{142}$

In addition to the technical analysis of the website activity, we also analyzed the use of the editing function by visitors. ${ }^{143}$ This analysis showed very little use of the Wiki functions. We found almost no evidence of stakeholder engagement with either the editing or the comment functions. Text editing within the Wiki platform was used predominantly by the AccountAbility team that supported the Wiki.

\section{b. Interim Reflections}

142 A dependent-samples t-test confirmed that the difference in the mean number of visits between days in proximity and not in proximity to the meetings, was statistically significant $-\mathrm{T}(16)=5.45, \mathrm{p}<0.001$. Appendix $\mathrm{C}$ provides the detailed data of the mean number of visits per day for each country that had a consultation group meeting (separately for days in proximity to the consultation group meeting and for days not in proximity to the meeting) from Sep. 23, 2009 to Mar. 10, 2010.

143 We received further confirmation to this finding from the in-depth interview with AcconutAbility team. 
Our findings suggest that there was some traffic on the Wiki (although not very large), but it did not translate into actual interaction with the Wiki. The Wiki operated as an information hub (a Web 1.0 structure) rather than as a web application that facilitates interactive information sharing and collaborative knowledge production (Web 2.0). ${ }^{144}$ We explore the reasons for this result in greater detail in the survey discussed in the next section. But it is already possible to make several comments. First, the relatively sparse usage of the Wiki seems to be consistent with the skepticism raised above about the capacity of the Wiki technology to facilitate a deliberative process without the appropriate social conditions, although the data do not allow me to pinpoint the exact reason for this result.

Second, the significant correlation between the timing of consultation workshops and the increase in the website activity suggests an interesting association between the two processes. It is possible that the Wiki contributed to the offline meetings by providing participants with easily accessible information. Although the Wiki may have acted as a valuable information source, however, it did not serve as a deliberative forum. This finding also underscores the importance of integrating the Wiki process with the offline consultation activity. Such integration could have generated more participation in the Wiki process. This argument is consistent with the argument that mixing online and offline methods contributes to the success of e-democracy projects ${ }^{145}$ and with the idea that Wikis can succeed as deliberative forums only if they are supported by other social-political processes.

\section{The Survey}

\section{a. Introduction and Method}

The survey sought to shed light on several questions related to the Wiki process. First, what motivated people to take part in the consultation project? Second, what can explain the relatively low level of actual participation in the Wiki? Third, what is the e-literacy profile of the participants?

\footnotetext{
${ }_{144}$ Andrew Chadwick, Web 2.0: New Challenges for the Study of E-Democracy in an Era of Informational Exuberance, 5 ISJLP 9 (2009).
}

145 GRÖNLUND \& ÅSTRÖM, supra note 13. Grönlund and Astrom measure success in terms of high participation, deliberative mode of discussion, and impact on policy. 
An invitation to participate in the survey was sent by the AccountAbility team to all the people who registered to the Wiki. ${ }^{146}$ The survey itself was posted on "Survey Monkey." Respondents received e-mails requesting them to answer the survey through an attached link. When a participant was done with the survey, answers were automatically transferred to the "Survey Monkey" dataset. ${ }^{147}$ I also conducted an interview with two members of the AccountAbility team and a member of the Technical Committee in September 2011 in which we discussed the findings of this study. The final sample included thirteen participants, six male and four female, aged twentyone to fifty-nine years. Five participants had a Master's or a professional degree and four had an advanced graduate degree or Ph.D. The majority of participants were employed; five were employed for wages and five were self-employed. Among the participants who were employed for wages, two were employees of a for-profit business, one was an employee of a not-for-profit charitable organization, one was an employee of an academic or research institution and one was an employee of state or local government. The majority of participants $(66.7 \%)$ stated that the region of their state of residence was Europe; others came from Asia, the Middle East and Australia. The relatively small size of the sample means that we should be careful in drawing conclusions from the survey and should consider it as exploratory, pointing to directions for future research.

\section{Findings}

\section{a. Basic Characteristics of the Social Dynamic of the Wiki Process ${ }^{148}$}

Eight Participants $(61.5 \%)$ were registered users of the AA10ooSES Wiki and five $(38.5 \%)$ were non registered users. The sample was relatively cohesive in terms of people linkage with

${ }^{146}$ A copy of the questionnaire that was distributed to the survey participants is available from the author by request.

147 The response rate was relatively low. Out of 218 registered Wiki participants, 13 have participated in the survey. The low response rate may be attributed to a lack of direct contact between the research group and the target community (more reminders could have generated more responses) and may also be indicative of a lack of sufficient interest in the Wiki project as a whole. It is also possible that the timing of the survey with an internal crisis in AccountAbility' contributed to the low response rate.

${ }^{148}$ The detailed statistics of the distribution of items measuring the social dynamic underlying the Wiki process are provided in Appendix D. 
AccountAbility. The majority of participants reported that they first heard about the AccountAbility AA10ooSES Wiki by means of the AccountAbility website $(38.5 \%)$ or a direct invitation from AccountAbility (30.8\%), a smaller percentage via an AccountAbility email list (23.1\%) and none by means of a Google search.

While more than half of the sample (seven subjects $(53.8 \%)$ ) reported participation in one of the offline workshops, their online engagement was relatively insignificant. The vast majority of participants reported ${ }^{149}$ that they visited the AA10ooSES Wiki once a month (75\%), with $66.7 \%$ reporting that they visited the AA10ooSES Wiki more extensively in the period prior to and during the workshop. The vast majority of registered users reported that they rarely participated in the actual editing of the AA10ooSES draft text, with $50 \%$ reporting that they never participated and $37.5 \%$ indicating that they participated once a month. This finding is inconsistent with our direct observation of the Wiki, in which we found no evidence of external editing of the Wiki and thus may reflect respondents' misunderstanding of the question. ${ }^{150}$

Participants were asked to rate how easy it was to find information within the Wiki on a 1 (easy) to 10 (difficult) point scale. The mean was $3.25(\mathrm{sd}=2.38),{ }^{151}$ indicating that participants did not face major difficulties whilst searching within the Wiki. This finding is again inconsistent with the lack of actual editing of the Wiki, which seems to be indicative of technical and informational difficulties. In addition, registered users were asked to rate the registration process in terms of ease of use on a 1 (extremely easy) to 10 (very difficult) point scale. The mean was $1.62(\mathrm{sd}=1.41)$ indicating that participants did not face major difficulties during the registration process. ${ }^{152}$

\footnotetext{
149 The figures are based on merged data of registered and non-registered users.

150 However, comments were sent directly to AccountAbility staff, so it is possible that the positive indication in the survey refers to this form of engagement (comment from a member of the Technical Committee).

${ }_{151}$ The figures are based on merged data of registered and non-registered users.

152 One of the study's objectives was to explore why people did not register to the Wiki and with respect to the registered group - why people did not participate in the actual editing. One segment of the survey asked the participants to rate several reasons that explain their decision on a 1 to 10 point scale, where 1 means that the reason does not explain the decision at all and 10 means that the reason fully explains the decision. Unfortunately we had $70 \%$ missing values among both registered and non-registered users and this data could not be used.
} 
b. Attitudes and Perceptions of the Wiki Process in General

The study examined individuals' attitudes and perceptions toward the Wiki process in general. Our findings indicate an intermediate (not strong enthusiasm) level of support for the use of Wikis in consultation processes. Participants were asked to rate their agreement with four statements on a 1 (low) to 10 (high) point scale. Table 1 presents basic descriptive statistics for these items and for the composite score, measuring support for the use of Wikis in consultation processes in general. 
Table 1: Attitudes and perceptions toward the value of the Wiki process in the context of consultation and rule-making

\begin{tabular}{|l|l|l|}
\hline Item & Mean & SD \\
\hline $\begin{array}{l}\text { To what extent do you think that the Wiki-based consultation } \\
\text { process would contribute to the broad acceptability of the ultimate } \\
\text { standard among its potential users? }\end{array}$ & 5.90 & 2.56 \\
\hline $\begin{array}{l}\text { To what extent do you think the Wiki-based consultation process } \\
\text { would improve the quality of the ultimate standard? }\end{array}$ & 5.80 & 2.35 \\
\hline $\begin{array}{l}\text { Would you recommend other international organizations, such as } \\
\text { the Global Reporting Imitative, use Wikis as part of their } \\
\text { consultation processes? }\end{array}$ & 5.90 & 3.07 \\
$\begin{array}{l}\text { Would you recommend a more extensive use of Wiki tools in } \\
\text { national consultations about national laws and regulations? }\end{array}$ & 5.00 & 2.91 \\
\hline $\begin{array}{l}\text { Support for the use of Wikis in the consultation processes in } \\
\text { general (composite score) }\end{array}$ & 5.65 & 2.66 \\
\hline
\end{tabular}

The means for the items range from 5.00 to 5.65 indicating an intermediate level of support for the use of Wikis-but not a very enthusiastic support. This result may reflect the intuition that Wikis can function well and generate democratic legitimacy only when conducted together with offline political processes.

\section{c. Measures of Web-Oriented Digital Literacy}

We also tried to evaluate the subjects' e-literacy. To this end, the survey included questions about the respondents' familiarity with six computer and internet-related terms. Participants were asked to rank their level of familiarity with the terms on a 1-5-point scale, from 1 (not familiar) to 5 (very familiar). The items were Advanced search, PDF, Spyware, WIKI, Cache, and RSS. ${ }^{153}$ Based on the high internal consistency of the six items (Cronbach's alpha=0.95), a composite score was also computed measuring the participants' Web-use skills. The mean of the of e-literacy composite measure was high $(\mathrm{m}=3.88$, $s d=1.23$ ) indicating that, overall, participants in the study had a high web-oriented digital literacy. ${ }^{154}$ The survey included three additional

${ }_{153}$ I relied in this context on the work of Eszter Hargittai on measures of e-literacy; see Eszter Hargittai \& Yuli Patrick Hsieh, Succinct Survey Measures of Web-Use Skills, 30(1) SOCIAL SCIENCE COMPUTER REVIEW 95 (2011).

154 The basic descriptive statistics for these six items and for the measure of e-literacy are reproduced in Appendix E. 
questions asking respondents about the approximate time they spend online each day, whether they have Facebook or Twitter accounts and their self-perception of their internet skills. We found that the majority of the participants (70\%) spent approximately more than two hours online each day, had a Facebook or Twitter account (70\%), and exhibited a high level of self-perceived internet skills, with $60 \%$ rating themselves as very skilled and 30\% rating themselves as experts.

\section{d. Measures of Voice and Expertise}

The survey also sought to elicit data about the respondents' perceptions of the underlying reasons for the legitimacy or acceptability of global standards such as the AA1oooSES. Participants were asked to rate their agreement with six statements on a 1 (strongly disagree) to 10 (fully agree) point scale, measuring the value of participation in creating legitimacy (Voice) and the importance of expertise in establishing legitimacy (Expertise). Two composite scores were computed measuring these factors (i.e voice and expertise). The findings indicate that the means for the items measuring voice ranged from 6.60 to 7.30 and the means for the items measuring expertise ranged from 6.10 to 7.40 , indicating high and similar levels of support for the claims that civic participation and expertise both have a crucial role in establishing legitimacy.

Table 2 presents basic descriptive statistics for the items and for the composite scores, measuring voice and expertise. 
Table 2: Descriptive statistics for the items measuring voice and expertise

\begin{tabular}{|c|c|c|}
\hline Items measuring voice & Mean & SD \\
\hline $\begin{array}{l}\text { The broad acceptability of global standards depends on the } \\
\text { inclusiveness of the consultation process that preceded their } \\
\text { publication. }\end{array}$ & 7.30 & 2.41 \\
\hline $\begin{array}{l}\text { The broad acceptability of global standards depends on the } \\
\text { establishment of mechanisms to ensure that the voice of the public is } \\
\text { being heard and given appropriate weight in the standard-setting } \\
\text { process. }\end{array}$ & 6.90 & 2.28 \\
\hline $\begin{array}{l}\text { The broad acceptability of global standards depends on whether thet } \\
\text { standard enjoys the support of a broad, transnational community of } \\
\text { stakeholders. }\end{array}$ & 6.60 & 2.55 \\
\hline $\begin{array}{l}\text { Voice } \\
\text { (composite score) }\end{array}$ & 6.93 & 2.39 \\
\hline Items measuring expertise & Mean & SD \\
\hline $\begin{array}{l}\text { The broad acceptability of global standards depends on the standard } \\
\text { being endorsed by reputable professional international organizations } \\
\text { such as the International Organization for Standardization or the World } \\
\text { Bank. }\end{array}$ & 6.10 & 3.03 \\
\hline $\begin{array}{l}\text { The broad acceptability of global standards depends on whether the } \\
\text { standard-setting process took into account the opinions of experts in the } \\
\text { field. }\end{array}$ & 6.40 & 2.55 \\
\hline $\begin{array}{l}\text { The broad acceptability of global standards depends on whether the } \\
\text { organization behind the standard has the necessary expertise. }\end{array}$ & 7.40 & 2.55 \\
\hline $\begin{array}{l}\text { Expertise } \\
\text { (composite score) }\end{array}$ & 6.63 & 2.68 \\
\hline
\end{tabular}

\section{e. Qualitative Measures}

Respondents were asked to suggest how they would improve the AA100oSES Wiki in a way which would have allowed more active participation by external stakeholders. The question was phrased as an open-ended inquiry, adding a qualitative aspect to the research. The respondents suggested several ways of improving the AA1OooSES Wiki. First, they highlighted the importance of making it more userfriendly. One participant noted in that context that he has recently "been involved in a debate in Linkedin and I found it much more easy to use [including] the traceability of the comments." Another 
suggested "using a special online platform similar to Facebook because "for many people, it is more intuitive." Another participant noted the importance of more involved central mediation: "To receive invitations more often from the organization that is in charge of the process; to organize specific working groups that could work online, in order to work on a specific issue or part of the standard/project." One participant was worried that opening the standard-setting process to multiple stakeholders could generate a standard that is too complex for some of the users: "Another reservation I have is that more participants may result in a more complex standard. I am interested in the use of the standard with SMEs [small-medium enterprises] and the existing standard is useful for its embodied principles, but the processes are too complex, potentially diverting scarce resources from front-line engagement initiatives.”

The issue of the user-friendliness of the Wiki-interface was also raised in the interview I conducted with AccountAbility (by a member of the Technical Committee). He noted that he thought that the Wiki was not very user-friendly and that this could constitute a significant barrier for intensive participation, given the time constraints of potential participants. He further noted that the Wiki was important for ensuring legitimacy for the whole process as anyone could participate. However, with the benefit of hindsight, the normative imperative does not mean people will participate, especially considering the nature of the emerging topic under consideration which in itself is very complex. The Wiki does not facilitate exchanging ideas. Also because of the transnational character of AccountAbility's work, language, in his opinion, was a big obstacle for many people.

\section{TECHNOLOGICAL INNOVATION, SOCIAL ENGINEERING, AND DEMOCRATIC DisILLUSIONMENT: LESSONS FROM THE CASE STUDIES}

One of the key insights of the case studies is that, in thinking about e-democratic practices, one should never lose sight of their social embeddedness. As was illustrated by the different case studies, from Consulting with Canadians to the transnational Wiki of AccountAbility, the capacity of the Internet to create digital environments for conversation does not guarantee a more enlightened public deliberative process. The case studies emphasize two key challenges in the effort to build working e-democracy schemes. The first challenge concerns the mobilization of broad public participation. The lack of broad civic participation was emphasized in all the case studies. Marc-André Roy of HC noted, in an illustrative comment, that participants to the consultations tended to be professionals: 
representatives of industrial firms, NGOs, members of professional associations, academics, or former employees. Broader participation from civic society was rare and limited to issues with strong public visibility. Such a participatory profile is inconsistent with one of the primary objectives of e-democracy.

The second challenge concerns the quality of the discussion, namely, how to utilize the digital environment in order to facilitate epistemologically and normatively complex debate? This difficulty was demonstrated both in the more conventional digital setting of Consulting with Canadians and in the more sophisticated setting of AccountAbility. ${ }^{155}$ The $\mathrm{HC}$ representative also noted that the biggest challenge with email consultations is that participants do not have the chance to hear views that are inconsistent with their own, making it difficult for Government to find the middle ground of what would be a "solution" that everybody could live with. Email consultation tends to produce polarizing views.

With respect to the first challenge of mobilizing public interest, the case studies offer several insights. First, all the interviewees highlighted the need for a proactive outreach approach. Both the HC and DFAIT representatives noted the need to create and maintain a Stakeholder Information Management system, which would include a list of interested citizens and could be used for outreach purposes. Such a system could be supported by an alert-type widget to inform citizens that a new consultation has been posted. A second idea in that context, raised by the interviewees from TransLink, was to design the consultation process in two phases; the first phase should be dedicated to building awareness of the policy dilemma, while phase two would consist of the consultation itself.

A third theme that emerged from the interviews concerned the potential use of social media tools. Both the interviewees in TransLink and AccountAbility emphasized the importance of linking the consultation process with dominant social media tools such as Facebook, Twitter and LinkedIn. Indeed, Facebook, for example,

\footnotetext{
155 This result is not a deterministic outcome of the Wiki technology. In other contextssuch as in Wikipedia-Wiki processes can demonstrate high reflexivity and a capacity to respond quickly to social and political events. Thus, for example, a Wiki value describing the tent protest, which took place in Israel during the summer of 2011, had been written only a few days after the protest erupted and was continuously updated during the protest. See Harriet Sherwood, Tel Aviv's 'Tent City' Protesters Dig in to Demand Social Justice, The GuARDIAN, Aug. 4, 2011, http://www.guardian.co.uk/world/2011/aug/o4/tel-avivtent-city-protesters; Wikipedia, http://he.wikipedia.org/wiki/האוהלים מחאת (last visited Jan. $25,2013)$. For a more successful experience of using Wiki as an e-democracy tool, see Matt Leighninger, supra note 10 , at 17.
} 
offers several social plug-ins such as Like, Subscribe and Comments, which allow users to "connect" their Facebook identity, friends and privacy to any site, and offer interesting opportunities in this context. ${ }^{156}$ Particularly useful is the Comment button, which enables users to comment on your site, and thus could facilitate a discussion which will take place simultaneously in both the Facebook domain and at the e-democracy portal. There seems to be a great potential, for example, in integrating Wiki processes, which are relatively complex and challenging from a cognitive perspective, with social platforms, such as Facebook and LinkedIn, that offer a more user-friendly interface. These platforms can also operate as a bridge between offline processes-such as the consultation workshops in our case-and the Wiki process. Many international and governmental agencies already use Facebook in order to connect with the civic society. ${ }^{157}$ Examples include the U.S. Environmental Protection Agency, the European Environmental Agency, the United Nations Environmental Program and the Global Reporting Initiative. ${ }^{158}$ These Facebook pages usually contain general details about these organizations' activities. The model suggested here is to create a dedicated Facebook page which would be directly associated with the Wiki process. Such a linkage could have a dual role: first, it could facilitate the bonding social dynamic necessary for lively deliberation; second, it could alleviate some of the technical-cognitive difficulties associated with Wiki technology. There are similar initiatives that seek to cope with these

\footnotetext{
${ }_{156}$ Social Plugims, FACEBOOK, http://developers.facebook.com/docs/plugins (last visited Jan. 25, 2013); Dave Morin, Announcing Facebook Connect, FACEBOOK (May 9, 2008, 12:32 PM), http://developers.facebook.com/blog/post/108; Brad Stone, Facebook Aims to Extend Its Reach Across the Web, N.Y.TIMES, Nov. 30, 2008, http://www.nytimes.com/ 2008/12/o1/technology/internet/o1facebook.html?pagewanted=all\&_r=0; see also Charles Petersen, In the World of Facebook, THE NEW YORK REvIEW OF BOOKS (Feb. 25, 2010), http://www.nybooks.com/articles/archives/2010/feb/25/in-the-world-offacebook/?pagination=false. For a more general (and critical) discussion of platform of this type see Robert Bodle, Regimes of Sharing, 14 INFORMATION, COMMUNICATION \& SOCIETY 320 (2011). These concrete reflections on Facebook are mine.

157 Cary Coglianese, Federal Agency Use of Electronic Media in the Rulemaking Process 12 (Univ. of Pa. Law Sch. Pub. Law Research Paper No. 11-32, 2011), available at http:// ssrn.com/abstract $=1911546$.

${ }_{15}^{8}$ U.S. Environmental Protection Agency, FACEBOOK, http://www.facebook.com/EPA (last visited Jan. 25, 2013); European Environmental Agency, FACEBOOK, http://www. facebook.com/European.Environment.Agency (last visited Jan. 25, 2013); UNEP, FACEBOOK, http://www.facebook.com/unep.org (last visited Jan. 25, 2013); The Global Reporting Initiative, FACEBOOK, http://www.facebook.com/pages/The-Global-ReportingInitiative/150847651598803 (last visited Jan. 25, 2013).
} 
cognitive difficulties by developing tools that could allow users to post their contributions to Wikis through their email software. ${ }^{159}$

A final theme that emerged in that context (particularly in the case studies of TransLink and AccountAbility) concerns the creation of a stronger linkage between the offline and online universes. In the AccountAbility case study, I found a significant correlation between the dates of the consultation meetings and increased visits to the Wiki. This finding indicates, first, that the Wiki may have contributed to the operation of the consultation meetings by providing participants with easily accessible information. Second, it also points to the importance of integrating the Wiki process with offline political processes. This could be achieved, for example, by encouraging participants to conduct online discussions prior to the meeting and maybe to return to the Wiki with some ex post reflections. One can also imagine the group as a whole posting a collective response on the Wiki as a kind of summary to the meeting. Overall, such integration could have provided the necessary peer support needed to counter the technical and sociological barriers involved in Wiki environment. This policy conclusion is also consistent with studies exploring the motivation of individuals to contribute to open source data-bases such as Wikipedia. These studies identify a plethora of motivations which can be associated with contributions to Wikipedia, including both utilitarian motivations (driven by an expectation for external reward) and altruistic (driven by concern for others). ${ }^{160}$ But the literature has also highlighted Wikipedians' sense of community as one of the strongest motivations to participate and contribute to the growth of Wikipedia. ${ }^{161}$ Altruistic motives seem to play an important role in the Wikipedia context. ${ }^{162}$ However, for altruistic motives to arise and to make sense, the deliberative process needs to take place within the context of a community. Such usage of mixed methods was also emphasized by the TransLink team although they did not develop explicit ways for linking the offline and online universes.

\footnotetext{
159 Chi, et al., supra note 119; Kong, et al., supra note 119.

160 Sheizaf Rafaeli \& YARON ARIEL, Online Motivational Factors: Incentives for Participation and Contribution in Wikipedia, in PSYCHOLOGICAL ASPECTS OF CYBERSPACE: THEORY, RESEARCH, APPLICATIONS 243, 250 (A. Barak ed., 2008).

${ }^{161} \mathrm{Id}$. at $257-58$.

${ }^{162}$ Shaul Oreg \& Oded Nov, Exploring Motivations for Contributing to Open Source Initiatives: The Roles of Contribution Context and Personal Values, 24 COMPUTERS IN HUMAN BEHAVIOR 2055 (2008).
} 
The second challenge concerns the deliberative quality of the discussion. A precondition for this result was to ensure that the interface of the Web portal was friendly and the information was accessible. Such technical issues could create a barrier even for highly e-literate participants, as was demonstrated by AccountAbility case study. Another way in which the deliberative quality of the discussion could be enhanced (which was suggested by the interviewee from HC) is to use some form of moderation. A good example for a project that seeks to develop such mediation services is Regulation Room, ${ }^{163}$ which was designed by the Cornell eRulemaking Initiative. Regulation Room seeks to provide an online environment for people and groups to learn about, discuss, and react to selected rules (regulations) proposed by U.S. federal agencies; as such, it seeks to complement the official Regulations.gov portal. ${ }^{164}$

Another mechanism (suggested by the TransLink case study) was to distinguish among participants with different levels of willingness to engage in cognitively demanding participatory exercises. TransLink's On-Line Advisory Panel allows TransLink to generate substantial numbers of public contributions through structured and relatively simple surveys. However, because the Advisory Panel is used mainly for polls, and does not allow for "open" comments or for interactive dialogue, its deliberative potential is quite limited. Differentiated engagement mechanisms could form an important tool for agencies seeking to develop engagement processes in heterogeneous communities.

What do these case studies tell us about the normative status of the idea of open government? Most of the institutions I studied demonstrated a deep normative commitment to the ideal of open government, even if they have not always been able to fulfill this commitment in practice. ${ }^{165}$ Such commitment was evident also in the approach of the participants in AccountAbility's Wiki to the use of Wikis as consultation devices. I found an intermediate-and-above level of support for the use of Wikis in consultation processes. This result may reflect the intuition that Wikis can generate democratic legitimacy only when conducted together with offline political

\footnotetext{
163 REgUlation ROOM, http://regulationroom.org (last visited Jan. 25, 2013).

164 See Coglianese, supra note 157 , at 16.

165 With the exception of DFAIT. For this commitment see, HEALTH CANADA POLICY TOOLKIT FOR PUBLIC INVOLVEMENT IN DECISION MAKING, supra note 65; Principles For Public Consultation, supra note 96; ACCOUNTABILITY, supra note 129.
} 
processes. We also found high and similar levels of support for the significance of civic participation and expertise in establishing legitimacy. Together, these two findings suggest that agencies should not rely exclusively on their expertise, but should continue to invest in developing consultation mechanisms and more general sensitivity to "voice."

One final and important message of the three case studies is the need for generating and maintaining political support for the idea of e-democracy and open government. Because the success of these schemes depends on proactive intervention-which is resourceincentive-it cannot take place without support. The distinction between the success story of TransLink and the more disappointing accomplishments of the Canadian Federal Government reflects, more than anything else, the impact of different levels of political backing.

\section{The New Vision of Punctuated CitizenshIP}

\section{A. Evaluating the Open Government Initiative}

The foregoing discussion demonstrates that constructing online deliberative mechanism is a non-trivial challenge. It is not enough to produce an innovative platform with a reasonably friendly interface to produce an inclusive and responsive deliberation process that meets the heightened civic aspirations of Obama and Popper.

Has Obama's Open Government Initiative succeeded in overcoming the institutional and sociological barriers that were highlighted by the three cases studies discussed above? Was it successful in its attempt to reinvigorate American democracy through wide-ranging experimentation with new ICTs? Because the U.S. initiative has taken a leading role in the global open government movement, this question is worth exploring. The three years that have passed since Obama took office allow some perspective on the accomplishments and remaining challenges of the initiative. In evaluating the performance of Obama's initiative, two questions seem particularly important. First, has the program improved the inclusiveness and responsiveness of the rule-making process within the participating agencies? This question seems critical in the dispute between Obama and Plato. Second, has it facilitated processes that can lead to future improvement, even if at this point in time the more elementary objectives of the initiative have not been achieved?

Because the Open Government Initiative continues to be a work in progress, there are relatively few studies that analyze it from an empirical perspective and none of these provide a comprehensive and 
systematic assessment of the program as a whole. Nevertheless, the picture that emerges from the current studies is that although the OG Directive has had significant social impact, it is unclear to what extent it has been able to produce deliberative processes that approximate the democratic ideal of informed and engaged citizenship.

Dennis Linders and Susan Copeland Wilson provided an assessment of the program a year after it was initiated. They note that the OG Directive has had several positive effects. First, it seems to have changed the default setting of government "from being closed, opaque and secretive, to becoming open, transparent, and participatory." This impression is confirmed by the data collected through the OG Directive's self-assessment tool, the OG Dashboard, which shows a high level of compliance of the federal agencies' OG plans with the OG Directive requirements. ${ }^{166}$ Second, the OG Directive has also been a trigger for the evolution of new communities of practice that bring together practitioners, advocates, subject matter experts, and academics to discuss the challenges of open governance. This new community collaborates on online platforms (particularly GovLoop.com), at conferences, and through various intertwining private initiatives. ${ }^{167}$ Third, "the [OG] Directive has helped spur the development and maturation of supporting technologies" and has accelerated the use of social media and Web 2.0 tools in the day-today activities of the government. ${ }^{168}$

\footnotetext{
${ }^{166}$ See Around the Government, THE WHITE House, http://www.whitehouse.gov/open/ around (last visited Jan. 26, 2013); Open Government Plan Evaluation Criteria, THE WHITE HOUSE, http://www.whitehouse.gov/open/documents/evaluation (last visited Jan. $26,2013)$. This impression receives further confirmation from the independent audit of the agencies' plans conducted by OpenTheGovernment.org. See Open Government Plans Audit, Final Updated Rankings, OPENTHEGOVERNMENT, https://sites.google.com/site/ opengovtplans/home/final-updated-rankings/final-rankings (last visited Jan. 26, 2013). These findings are more critical in their assessment of the agencies' plans but still reflect significant activity following the release of the OG Directive. See also Bertot John Carlo, et al., Measurement of Open Government: Metrics and Process, IEEE COMPUTER SOCIETY, PROCEEDINGS OF THE 45TH HAWAII INTERNATIONAL CONFERENCE ON SYSTEM SCIENCES 2491 (2012). Additional data regarding the impact of the OG Directive was provided by Vivek Kundra in his talk, Creating the Digital Public Square, June 14, 2011 (copy on file with the author). He notes that Hits to Data.gov have grown from 2.1 million in May 21, 2009 to 204.3 million in May 21, 2011, the number of Open data leads in Federal agencies have grown in this period from 24 to 396, the number of States offering open data sites have grown in this period from o to 29 .

167 Examples include the Open Government Study Group (http://www.meetup.com/ Opengovstudy) and the OpenGov Community Summit Series (see, e.g., the EPA meetinghttp://www.meetup.com/Opengovstudy/events/14844047).
} 
The picture is less clear regarding the extent to which the OG Directive has succeeded in reinvigorating the democratic practices of the agencies in a deep and substantial sense. Indeed, members of the OpenTheGovernment.org group note that more work needs to be done in order to evaluate the implementation of open government by developing suitable metrics and using them to measure the practices of the agencies. ${ }^{169}$ Linders and Copeland highlight two potential obstacles that may undermine the capacity of the Open Government initiative to instigate significant changes in the democratic practices of the U.S. government. First, there is uncertainty whether there is sufficient political support to bring the OG Directive to the next step and produce long-lasting cultural change within the federal agencies, which can withstand the conflicting demands these agencies are facing (e.g., to deliver tangible results in the area of their core functions or to focus on cost savings). ${ }^{170}$

Second, at times, the OG Directive discourse seems to reflect a deterministic belief in the capacity of new Web 2.0 technology to generate social change. This technological focus is particularly evident in the work of the highly influential former White House Chief Information Officer Vivek Kundra, ${ }^{171}$ and in Tim O'Reilly's book,

168 Dennis Linders \& Susan Copeland Wilson, What is Open Government?: One Year After the Directive, 12 AM. INT'L. CONF. PROC., 262, 262-63 (2011).

${ }^{169}$ See Open Government Plans Audit, Evaluating Open Government, OPENTHEGOVERNMENT, https://sites.google.com/site/opengovtplans (last visited Jan. 26, 2013).

170 Linders \& Wilson, supra note 169, at 269. Similar worry about the political sustainability of OG initiative is expressed by Peter Shane in: Peter M. Shane, Empowering the Collaborative Citizen in the Administrative State: A Case Study of the Federal Communications Commission, 65 U. MLAMI L. REV. 483, 501 (2011).

${ }^{171}$ See, e.g., Vivek Kundra, Government 2.0: Advancing America into the 21st Century and a Digital Future (Apr. 28, 2009), available at https://cio.gov/vivek-kundra-testimony-ongovernment-2-o-advancing-america-into-the-21st-century-and-a-digital-future ("Making the information and operations of government more open and accessible will drive accountability, performance, and engagement. And through currently available technology - search tools, online video, social networking - we now have the means to do so. Democratizing government data will engage citizens and fundamentally change how government operates. The availability of raw, machine-readable data in a variety of open, standards-based formats involves the citizenry in new ways and empowers them to be "cocreators", alongside the government, of new applications, new ideas, and new ways of doing business. By enabling the "mash up" of data feeds we can create value both for the government and for the country. Innovation can occur much faster and at a lower cost if we move to democratize our data"). Similar emphasis on technology is apparent from his public lectures. See, e.g., Vivek Kundra, Creating the Digital Public Square (June 14, 2011); Chopra, Aneesh, Vivek Kundra, and Phil Weiser, Innovation for America: 
Government As a Platform. ${ }^{172}$ But this technological focus seems to skirt the sociological and psychological barriers to digital democratization. ${ }^{173}$ Indeed, studies that examine more closely the democratic quality of the collaborative processes engendered by the OG Directive report a somewhat disappointing picture. Peter Shane, for example, has studied the attempts of the Federal Communications Commission (FCC) to develop collaborative processes in the spirit of the OG Directive. ${ }^{174}$ The FCC has established a new Electronic Comment Filing System (http://apps.fcc.gov/ecfs) and developed a new portal, OpenInternet.gov, that offers easy access to explanations of the FCC's notice of inquiry on the open Internet. ${ }^{175}$ But as Shane notes, the FCC still has not figured out how to resolve what is the most important strategic challenge of the agency: "how to generate public interest in and demand for new interaction opportunities." Shane notes that his informal conversations with agency staff revealed recurrent expressions of hope for some effective public voice "to serve as a counterbalance on the voices of industry and inside-the-beltway insiders, who hardly need new media to make their views effectively known within the agency. The question is how to alert potential contributors that the FCC is prepared to listen to their input."

A similar mixed picture emerges from Ganapti and Reddick's recent study, which examined the extent to which state governments in the U.S. have adopted open e-government initiatives. They

Technology for Economic Growth and Empowering Americans, presented at Brookings Institution, Alfred Taubman Forum (June 8, 2010), available at http://www.brookings.edu/ /media/ events/2010/6/08\%20science\%20technology/20100608_science_technology.pdf. In another reflection of his technological fixation, Kundra talks about a culture gap between consumers and government which is captured the conflicting phrases: "There's an app for that" /"There's a form for that[.]"

\footnotetext{
international level"). Online Deliberation, 5 ISJLP 43 (2009).

${ }^{174}$ Shane, supra note 170 , at 484.

175 Shane, supra note 170 , at 490-91, 495-96.
}

${ }^{172}$ Tim O'ReILly, GOVERNMENT AS A PLATFORM Ch. 1 (2010), available at http:// opengovernment.labs.oreilly.com/cho1.html (advocating the notion of "Government 2.0" which is defined as "the use of technology-especially the collaborative technologies at the heart of Web 2.0-to better solve collective problems at a city, state, national, and

173 See Linders \& Wilson, supra note 168, at 265; Cynthia R. Farina, et al., Rulemaking in 140 Characters or Less: Social Networking and Public Participation in Rulemaking, 31 PACE L. REv. 382, 389-90 (2011); Oren Perez, Complexity, Information Overload and 
surveyed Chief Information Officers (CIOs) of state governments to identify the extent of such adoption. Although a majority of the CIOs felt they have made significant progress in achieving a high degree of transparency, they did not feel as strongly about citizen participation. The results of the survey show that extensive use of open egovernment participatory methods is not very common. Furthermore, with respect to the issue of transparency, the CIOs provided no indication of the extent to which the data that have been disclosed through these new initiatives were used by the public. The sociological and cognitive challenges of using Web technology to facilitate democratic processes, especially in the context of e-rulemaking, are also emphasized by Farina et al., drawing on their experience with the Regulation Room Project. ${ }^{176}$ Indeed, the vast investment, in both technological innovation and human intermediation, which was made in this project to facilitate online civic engagement (based on the infrastructure of Regulations.gov), signals how difficult it is both to attract participants to Web-based democratic projects and to facilitate and manage the discussion so as to improve its epistemic quality. The mobilization problem was noted also by Stromer-Galley, et al., in a study of e-rulemaking. They emphasize as a further problem the potential gap between the high rhetoric of Open Government Initiative and the culture of the federal agencies. One of the obstacles they routinely encountered when discussing their project with officials, they note, was:

[A] sentiment that comments from the public were burdensome and ill-informed. Officials were concerned that a deliberative project like ours would likely only lead to more work with seemingly little payoff. Unless government officials come to see value in genuinely seeking comment from citizens, projects like ours will necessarily be limited. ${ }^{177}$

The lack of reflexivity with respect to the social-political effect of the OG Directive, which was evident in Ganapti and Reddick's work, places the OG Directive program as a whole in doubt. The Open Government Initative would completely miss its goal if it disregards the social effects associated with the wave of technological innovation

\footnotetext{
${ }_{176}$ See Farina, et al., supra note 173, at 396-416; REgULATION ROOM, supra note 163.

177 Jennifer Stromer-Galley, et al., Deliberative E-Rulemaking Project: Challenges to Enacting Real World Deliberation, 9 J. OF INFO. TECH. \& POL. 82, 93 (2011).
} 
it has generated, focusing instead only the program's more tangible (and arguably more limited) achievements. ${ }^{178}$

\section{B. Punctuated Citizenship as an Alternative Model for Citizenship in the Digital Era}

The notion that citizens could maintain a stable level of epistemic alertness and internal motivation, which would enable them to continuously monitor opportunities for online political engagement and to actually use these opportunities in a way that fully uses their cognitive and social capabilities, seems highly naïve. Both the case studies and the empirical evaluation of the OG Directive program seem to support this skeptical outlook, which presents a theoretical and pragmatic challenge to the open government and e-democracy movements. ${ }^{179}$ This outlook also questions the capacity of open government and e-democracy to generate wide-ranging participatory practices and to improve the ultimate decisions of the political process.

Professor Stephen Coleman of the University of Leeds offers an alternative analytic framework that could be used to analyze the interaction between government and citizen in the Internet era, which rejects Plato's total skepticism of the capacity of citizens to take part in the political process. Coleman argues that the web-mediated interaction between government and citizens could be analyzed through a conceptual scheme that distinguishes between three citizen archetypes. These serve as normative-analytic constructs. The "infolite" citizen is not interested in acquiring comprehensive information pertaining to political questions and draws on various heuristics in order to make political decisions. "Info-lite" citizenship represents a

\footnotetext{
178 Sukumar Ganapati \& Christopher Reddick, Open Government Achievement and Satisfaction in US Federal Agencies: Survey Evidence for the Three Pillars, 34 J. OF EGOVERNANCE 193, 196-98, §§ 6, 7 (2011).

179 Professor Ronald J. Krotoszynski of the University of Alabama School of Law, another recent proponent of the skeptic approach, suggests that rather than commit to generic process values that will apply always and everywhere, the open governance approach should be used more selectively, tailoring the process to the precise nature of the problem at issue. Otherwise, he argues, the commitment to openness could cost us in terms of securing effective, competent governance. See Ronald J. Krotoszynski, Transparency, Accountability, and Competency: An Essay on the Obama Administration, Google Government, and the Difficulties of Securing Effective Governance, 65 U. MIAMI L. REV. 449, 453 (2011).
} 
highly passive form of citizenship. ${ }^{180}$ The "push-button citizen" reflects a more active but still epistemologically shallow form of citizenship. Citizens of this type are willing to take part in nondeliberative political actions; they will petition the government, take part in referenda if offered the opportunity, and use their right to vote in regional and national elections. But the democracy such citizenship constitutes is still far from the ideal of reflective, deliberative democracy, offering instead a "crude mechanism for majoritarian head-counting." 181 The last form of citizenship described by Coleman is "actualizing citizenship," a form that envisions citizens being guided by a post-deferential attitude toward authority and willing to regard political communication as a non-hierarchical, dialogical process. Actualizing citizens accept responsibility for the production and management of their social and political identities and regard themselves as empowered to be fully present in the processes of government decision-making. ${ }^{182}$

According to Coleman, the technologies that government uses should be sensitive to these different ideal-types of citizenship. To the extent that governments and other social players want to facilitate and encourage "actualizing citizenship," they must develop technological means that respond to the needs and concerns entailed by this form of citizenship. In particular, governments need to view e-citizenship as a "democratic space where anyone can stake a claim to be heard and respected and all proposals have a chance of being acted on."183 The

\footnotetext{
180 Stephen Coleman, Making the E-Citizen: A Socio-Technical Approach to Democracy, in CONNECTING DEMOCRACY: ONLINE CONSULTATION AND THE FUTURE OF POLITICAL COMMUniCation 380, 380-83 (Stephen Coleman \& Peter Shane eds., 2012); See also the discussion in Shane, supra note 170, at 502-03.

${ }^{181}$ Coleman, supra note 180 , at $384-85$.

182 Coleman, supra note 180 , at 385-386. The idea of "actualizing citizenship" carries close resemblance to the notion of "Socratic citizenship" (which is attributed to the "real" Socrates). One of the key ingredients of Socratic citizenship is the conversations Socrates had undertaken with his fellow citizens, through which he sought to cultivate a sense of self-critique and self-observation in his interlocutors. David D. Corey, Socratic Citizenship: Delphic Oracle and Divine Sign, 67 THE REv. OF POL. 201, 205 (2005). The cultivation of individual capacity for critical introspectiveness is prerequisite for the emergence of a reflexive public sphere and in that sense is a political activity. See James Bohman, Expanding Dialogue: The Internet, the Public Sphere and Prospects for Transnational Democracy, 52 THE Soc. REv. 131, 136 (2004) (explicating the idea of reflexivity within the public sphere).

183 Coleman, supra note 180 , at 391.
} 
vision underlying Coleman's actualizing citizen is very close to that underlying Obama's Open Government Initiative. ${ }^{184}$

One of the difficulties with Coleman's typology, and especially with its emphasis on the idea of "actualizing citizenship" (which intersects, as we have seen above, with Obama's notion of open government) is that, although he conceives it in normative terms, it might be misinterpreted as carrying a deterministic message-denoting a technologically driven process of political progress. ${ }^{185} \mathrm{I}$ think that it would be more useful to replace Coleman's scheme of archetypes with a hybrid notion of citizenship, which better captures the way citizenship is experienced in contemporary politics. I use the term "punctuated citizenship" to capture this hybrid experience. The notion of punctuated citizenship recognizes that Coleman's three ideal types of citizenship are present in each of us, and as deeply political creatures ${ }^{186}$ we ceaselessly move among the three states. ${ }^{187}$ The way in which our latent political capacity is activated depends on various internal and external variables that are still not well understood.

184 The following quote from President Obama's speech on open government partnership at the Waldorf Astoria Hotel, in New York City, New York on Sep. 20, 2011 is instructive: "Here in the United States, we've worked to make government more open and responsive than ever before. We've been promoting greater disclosure of government information, empowering citizens with new ways to participate in their democracy. We are releasing more data in usable forms on health and safety and the environment, because information is power, and helping people make informed decisions and entrepreneurs turn data into new products, they create new jobs. We're also soliciting the best ideas from our people in how to make government work better." Brian Sidler, Opening Remarks by President Obama on Open Government Partnership, THE CRITICAL POST - CHICAGO (Sept. 21, 2011), http://thecritical-post.com/blog/2011/og/president-obamas-speech-on-open-

government-partnership-at-waldorf-astoria-hotel-new-york-city-new-york-20-september2011-transcript-text-tcpchicago (last visited Jan. 26, 2013).

185 For the idea of progress see ROBERT A. NISBET, HISTORY OF THE IDEA OF PROGRESS (Transaction Publishers 2d ed. 1994).

186 On the idea that humans are inherently political animals see, James H. Fowler, et al., Causality in Political Networks, 39 AM. POL. Res. 437 (2011); PETER K. HATEMI \& ROSE MCDermott, Man is by Nature a Political ANimal: Evolution, Biology, and Politics (Univ. of Chi. Press 2011). This claim goes back to Aristotle who argued that if we are naturally social, then we must be naturally political. Josh Chafetz, The Political Animal and the Ethics of Constitutional Commitment, 124 HARVARD L. REV. F. 1, 6 (2011).

187 The idea of punctuated citizenship thus has much in common with the notion of "multiple selves," developed by Ayres and Braithwaite. IAN AYRES \& JOHN BRAITHWAITE, RESPONSIVE REGULATION: TRANSCENDING THE DEREGULATION DEBATE 21-22, 33-34 (Oxford U. Press. 1992). 
The idea of punctuated citizenship also recognizes that individuals have limited epistemic, attentive, and social-motivational resources and, therefore, their political engagement is likely to be punctuated and unstable. Our cognitive fallibility means that we are not able to remain constantly within the emotionally and cognitively intensive state of "actualizing citizenship." But our ingrained political sensitivities also imply that we cannot maintain a completely passive approach to politics. This argument rejects, therefore, the idea that "lurking" could be a permanent personality trait. ${ }^{188}$ While people may differ in their political assertiveness, we all share a latent political capacity. Political activity at the individual level is likely, therefore, to be characterized by long periods of a relatively low level of engagement that are punctuated by short bursts of more intense political activity. ${ }^{189}$ The model of punctuated citizenship recognizes, however, that even in our most alert political state, we remain cognitively bounded. ${ }^{190}$ Nevertheless, the greater individual willingness in this alert political state to enter into a dialectical Socratic dialogue with one's peers opens up the opportunity to extend the boundaries of our public understanding through a critical and open dialogical process. ${ }^{191}$

The idea of punctuated citizenship also reflects a broader sociological phenomenon. Political processes are likely to be

188 See Michael Muller, Lurking as Personal Trait or Situational Disposition: Lurking and Contributing in Enterprise Social Media, CSCW '12: PROCEEDINGS OF THE ACM 2012 CONFERENCE ON COMPUTER SUPPORTED COOPERATIVE WORK 253 (2012) (showing that people may lurk in some communities and contribute in other communities); Jenny Preece, et al., The Top Five Reasons for Lurking: Improving Community Experiences for Everyone, 20 COMPUTERS IN HUM. BEHAV. 201, 217 (2004) (arguing that lurkers may be transformed into contributors through appropriate incentives and interface design).

189 The inspiration from this argument comes from the literature on punctuated equilibrium in evolution theory. See Stephan Jay Gould \& Niles Eldredge, Punctuated Equilibrium Comes of Age, 366 NATURE 223 (1993); Elaine Romanelli \& Michael L. Tushman, Organizational Transformation as Punctuated Equilibrium: An Empirical Test, 37 THE ACAD. OF MGMT. J. 1141 (1994).

190 See Michael Slote \& Philip Pettit, Satisficing Consequentialism, 58 Proceedings of THE ARISTOTELIAN SOC'Y, Supp. Vols. 139 (1984), available at http://www.princeton.edu/ $\sim$ ppettit/papers/1984/Satisficing\%20Consequentialism.pdf; Herbert A. Simon, Invariants of Human Behavior, 41 ANN. REV. OF PSYCHO. 1, 17 (1990).

191 See GaReTH B. MATTHEWS, The Epistemology and Metaphysics of Socrates, in THE OXFORD HANDBOOK OF PLATO 133 (Gail Fine ed., 2008) (explicating the response to the problem of Elenchus in the Dialogue Meno); See also Plato, MENO 85c-d (Benjamin Jowett trans. 2006). 
punctuated because society at large has limited capacity for coordinated political action. Society cannot sustain epistemologically and socially demanding deliberative processes simultaneously in multiple subject areas. To give a recent example, it was remarkable to see how the tents' protest that took place in Israel in the summer of 2011, died with the arrival of fall. Somehow, all the energies, which at the height of the protest seemed endless, disappeared in a surprisingly coordinated fashion in the fall of 2011. ${ }^{192}$

\section{GOVERNING E-DEMOCRACY: POLICY SIGNPOSTS AND REGULATORY CHALLENGES}

To the extent that one undertakes a normative commitment to support a vision of deep democratic engagement of the type envisioned by Obama and Popper-and it is difficult to support this conception of democracy merely on instrumental grounds-the idea of punctuated citizenship requires a different approach to civic engagement. It means that meeting the objective of open government and e-democracy requires strategies that recognize the punctuated nature of democratic engagement and seek to find the proper means to respond to it. In particular, this vision rejects a technologically deterministic interpretation of the idea of open government. It means that people can be drawn into political engagement, but only in a highly selective and somewhat unpredictable way, and that as a society we need to make difficult choices in selecting those issues about which we want to generate wide-ranging and epistemologically complex dialogical processes.

In this concluding section I want to highlight several strategies that respond to the challenge of punctuated citizenship and to discuss the regulatory challenges they generate.

\section{A. Five Policy Signposts for Fulfilling the Vision of e-Democracy}

\footnotetext{
192 For the story of the Israeli summer of protest see Batsheva Sobelman, As Tel Aviv Tent City Folds, Israel Activists Debate Next Step, L.A. TIMES, September 07, 2011, available at http://articles.latimes.com/2011/sep/07/world/la-fg-israel-tent-protest-20110908; Harriet Sherwood, Israeli Protests: 430,ooo Take to Streets to Demand Social Justice, THE GUARDIAN, Sept. 4, 2011, available at http://www.guardian.co.uk/world/2011/sep/ 04/israel-protests-social-justice; Eyal Press, Rising Up in Israel, THE NEW YORK REVIEW OF BOOKS, Nov. 24, 2011, available at http://www.nybooks.com/articles/archives/2011/ nov/24/rising-israel/?pagination=false. For an application of the concept of punctuated equilibrium to political studies see Frank R. Baumgartner, et al., Punctuated Equilibrium in Comparative Perspective, 53 AM. J. OF POL. SCI. 603 (2009); Carsten Jensen, Policy Punctuations in Mature Welfare States, 29 J. OF PUB. POL'Y 283, 283 (2009).
} 
(1) Building motivation. Motivation cannot simply be assumed. It is a scarce resource. One way to build motivation is by linking the offline and online universes-allowing the sterile online sphere to benefit from the unique vitality of face-to-face interaction. This can be accomplished by using social media software or by tapping into the motivational resources of existing online communities. Another important and necessary strategy should focus on developing outreach campaigns (both online and offline) that seek to recruit relevant stakeholders.

(2) Recognizing the limits of the online medium: human and technological intermediation. One of the important lessons of the case studies and of the experimental work of groups such as the Cornell Regulation Room is that achieving high-quality conversation online requires intermediation, both in facilitating the discussion and in trying to extract common themes from it as it unfolds. Intermediation is also needed to counter some of the negative "baggage" of the online environment. As Farina, et al., point out, although the new Web 2.0 technology can enable and support informed dialogical conversation, it also comes with "a set of habits and expectations that do not serve users well when the goal is informed and thoughtful engagement in complex policy issues." 193 The authors emphasize in this context the low attentional investment that characterizes most people's Web usage pattern and the pivotal role of voting (and similar practices) in the current democratic culture. ${ }^{194}$ Intermediation can be conducted either through human intervention or through the use of natural language processing (NLP) technology. ${ }^{195}$ Other forms of technological intermediation may involve the use of games in order to elicit attention. ${ }^{196}$

193 Farina, et al., Rulemaking in 140 Characters or Less: Social Networking and Public
Participation in Rulemaking, 31 PACE L. REV. 382, 392-93.

194 Which means that people tend to stay only for very limited time on any website they visit: "What [users] actually do most of the time (if we're lucky) is glance at each new page, scan some of the text, and click on the first link that catches their interest." Id. at 440. A second problematic predisposition is that "American popular culture equates public participation in government decision making with voting." Id. This predisposition was reproduced in the net through such mechanisms such as Facebook like, ideascale.com and epetitions.direct.gov.uk.

195 For the use of NLP technology in an e-democracy context see, e.g., Stromer-Galley et al., supra note 177 , at $86-87$.

196 "Gamification" is an informal umbrella term for the use of video game elements in nongaming systems to improve user experience and user engagement. See Sebastian Deterding, et al., Gamification. Using Game-Design Elements in Non-Gaming Contexts, 
(3) Selectivity. The investment needed to create the conditions for high quality dialogue means that government, or any other political agent committed to the idea of e-democracy, would probably need to prioritize its civic engagement policy. It would need to select those issues that justify more intensive public deliberation and adopt a proactive outreach policy with regard to these issues, of the type developed and applied by the Cornell Regulation Room group. ${ }^{197}$

(4) Countering computer anxiety and developing differentiated interfacing. Whereas technological innovation should not be seen as a panacea to all the dilemmas surrounding e-democracy, it can play a crucial role in responding to problems of e-literacy and computer anxiety. New technologies that respond to that challenge, such as Google Moderator, Idea Scale, and Debategraph are continuously being developed, as well as models that can improve the underlying structure of mass deliberation. ${ }^{198}$

(5) Supporting political intermediaries. Without underestimating the argument on behalf of collective public wisdom, it seems that political intermediaries (NGOs, academics, journalists, business associations) will continue to play an important role in processes of democratic engagement. As some of the interviewees noted, we must bear in mind that large corporations and other powerful institutions have their own ways of making their voice heard. Neither should the new Web powerhouses-Google, Wikipedia, and Facebook-be necessarily trusted as authentic representatives of the civic society. To be able to play their role in the political process, civic society organizations need continuous support. Simply making the information available online (even in machine readable form) and creating routes for participation does not mean that civic organizations (or their members) can actually use these opportunities. Taking part in e-rulemaking or in environmental impact assessment processes or simply monitoring existing regulatory programs drawing on new data portals, in an epistemologically responsible way, is a costly and resource intensive activity. An interesting model of civic

CHI EA '11: CHI '11 EXTENDED ABSTRACTS ON HUMAN FACTORS IN COMPUTING SYSTEMS (2011). It was used by TransLink in one of their consultation projects.

197 Cynthia R. Farina, et al., Rulemaking 2.o, 65 U. OF MIAMI L. REv. 395 (2011).

${ }^{198}$ See Pietro Speroni di Fenizio \& Derek Paterson, Don't Vote, Evolve!, in ElectRonIC PARTICIPATION, PROCEEDINGS OF THE SECOND IFIP WG 8.5 INTERNATIONAL CONFERENCE, EPART'10, at 13 (Efthimios Tambouris, et al. eds., 2010); W. Ben Towne \& James D. Herbsleb, Design Considerations for Online Deliberation Systems, 9 J. OF INFO. TECH. \& POL. 97 (2012). 
support, which could be drawn upon in this context, is the Canadian Participant Funding Program. This program supports individuals and non-profit organizations interested in participating in federal environmental assessments in the context of the Canadian Environmental Assessment Act (S.C. 1992, c. 37). ${ }^{199}$

\section{B. Governing E-Democracy: The Challenge of New Techno-Political Intermediation and the Emergence of Techno-Regulatory Hybrids}

The recognition that e-democracy would probably not flourish without hierarchical ordering highlights an additional challenge for the governance regime that will oversee the open government project: creating mechanisms that could monitor those who coordinate the processes of engagement. The hidden work of the technological and sociological intermediaries associated with e-democracy projects can greatly affect the way in which the political process unfolds. The multiple and non-trivial selections associated with the intervention of these intermediaries-whether in the editing of content, its visual presentation, or in the technical structuring of the website interfacemay influence in various ways the deliberation or consultation process. I want to highlight three regulatory dilemmas that seem particularly prominent in this context: first, structuring the linkage between the offline and online worlds; second, controlling the prioritization of issues for extra investment; and third, regulating the hidden techno-social selections which underline any web-based democratic process.

Political interaction will increasingly take place in both physical and virtual places. One of the implications of this phenomenon is that the definition of the 'place' in which the political meeting is occurring will become blurred. This phenomenon is likely to generate various legal questions in terms of protecting the integrity of the political process (e.g., consultation). How does one protect basic political rights such as notification, accessibility and the right for 'voice' when the boundaries of the relevant political venue are becoming fuzzy? For example, need notification be made in both the virtual and physical worlds, or just in one of them? What are the criteria for accessibility that apply in both domains? What are the obligations that apply to governments in facilitating 'voice'-does government have to make

\footnotetext{
199 See Participant Funding Program, CANADIAN ENVIRONMENTAL ASSESSMENT AGENCY, http://www.ceaa-acee.gc.ca/default.asp?lang=En\&n=E33AE9FB-1 (last accessed Dec. 20, 2012).
} 
any comment that was made in the physical domain (e.g., town hall meeting) available for participants in the virtual space-and at what pace, i.e., in real time or within some acceptable interval? These questions still do not have good answers under current administrative law doctrine. ${ }^{200}$

The prioritization of topics creates a different dilemma because it challenges the traditional legal quest for neutrality. It is not clear what would be the meta-criteria according to which such prioritization would take place. Should we leave this decision to the government agency? Should we subject it to public deliberation process? Or maybe, in order to respect the neutrality principle, should we employ some randomization device?201

Regulating the hidden techno-social selections associated with the design of web-based democratic schemes creates an even more difficult and wide-ranging dilemma. Consider, for example, the potential oversight problem associated with the use of natural language processing technology and semantic web agents. Such technologies could be used to assist users in retrieving information using natural language, to assist organizers of e-rulemaking to categorize issues and to summarize completed discussions and to offer suggestions for new topics for potential discussion based on previous engagements. ${ }^{202}$ Paradoxically, should the open government movement be successful in expanding the scale of civic participation, it will increase the pressure on public agencies to use NLP technology in order to allow them to cope with the increasing information load.

200 Virginia Freedom of Information Act, § 2.2-3707 prohibits, for example, conducting meetings of public bodies through electronic means where the members are not physically assembled. However, these limitations do not prevent members of the public from participating in a meeting electronically. Subsection $A$ of $\S 2.2-3708$ states that " $[n]$ othing in this section shall be construed to prohibit the use of interactive audio or video means to expand public participation." For discussion see Beck v. Shelton, 267 Va. 482, 490-491, 593 S.E.2d 195 (2004).

201 For the use and abuse of randomization in law see, OREN PEREz, The Institutionalization of Inconsistency: from Fluid Concepts to Random Walk, in PARADOXES AND INCONSISTENCIES In LAW (Oren Perez \& Gunther Teubner eds., 2006).

202 See Stromer-Galley et al., supra note 177, at 86; James Hendler, Agents and the Semantic Web, 16 IEEE INTELLIGENT SYSTEMS 30 (2001); WILLIAM YANG WANG \& KaTHLEEN R. MCKeOWN, "Got you!": Automatic Vandalism Detection in Wikipedia with Web-Based Shallow Syntactic-Semantic Modeling, ASSOCLATION FOR COMPUTATIONAL LINGUISTICS, PROCEEDINGS OF THE 23RD INTERNATIONAL CONFERENCE ON COMPUTATIONAL LINGUISTICS 1146 (2010) (discussing the use of semantic web-agents to distinguish vandal from non-vandal contributions in a Wiki environment). 
But the use of such technologies in consultation processes also raises some difficult questions from the perspective of administrative law doctrine. In particular, may a regulatory agency reasonably rely on web-agents to summarize the content of conversation?203

These multiple regulatory challenges do not have ready answers under current administrative law doctrines. One possible response is to expand the scope of the deliberative process to include also these generic architectural questions. But this solution faces serious pragmatic problems. First, the costs of such expansion may be prohibitive. Clearly, it would be unrealistic to establish a consultative process for each socio-technical choice aiming to make the primary consultation process more accessible. Another possible solution is transparency. In the spirit of the open-data movement, the designers of an e-democracy scheme should be completely transparent about the technological and sociological infrastructure of the engagement tool (including the code data). The problem with this proposal is that, although in theory it opens the possibility of critique, the prospects for such critique being realized are extremely low given the cognitive burden such critique would require. Another solution focuses on the facilitation of reciprocal monitoring between various political intermediaries, including the new type of techno-political mediators associated with e-democracy schemes. This solution would require, however, finding the ways to support the work of political intermediaries who have the capacity to criticize also the more technical aspects of e-democracy design.

But maybe the solution lies elsewhere-in designing novel hybrids involving both traditional legal oversight tools and computerized regulatory agents such as computational trust mechanisms. Smart et al., discuss in a similar spirit the question of whether the Internet is capable of fundamentally transfiguring the space of human thought and reason. ${ }^{204}$ In particular, they examine the extent to which notions of environmentally-extended cognition apply to the world of networkenabled information appliances and network-accessible resources. They argue that, under certain circumstances, the "informational and technological elements of a large-scale information network, such as

203 The recent decision of the Canadian Supreme Court in Halifax (Regional Municipality) v. Nova Scotia (Human Rights Commission), [2012] 1 S.C.R. 364, limits the Court authority to intervene in decisions of administrative tribunals on grounds of lack of reasonableness. But would this policy of deference hold also in such cases involving the delegation of discretionary powers to software agents?

204 PAUl R. SMaRT ET AL., The Extended Mind and Network-Enabled Cognition 1 (2008), http://eprints.soton.ac.uk/266649/1/Network\%2DEnabled_Cognitionv17.pdf. 
the World Wide Web, can form part of the material substrate that undergirds a human agent's mental states and processes." 205 Similarly, I would argue that, in imagining the legal landscape that would fulfill the task of regulating the future platforms through which the vision of open government will be realized, we should not limit ourselves to the traditional doctrines and institutions of administrative law but imagine a complex hybrid network consisting of legal institutions and players, legal doctrines and varied computerized agents. This view may require us to rethink our basic conception of law, but this may also be the only option to regulate a field that is also challenging our traditional understanding of politics. 


\section{Appendix A}

The Consultation Workshops dates and locations

1. South Africa, Johannesburg (1/10/ 2009)

2. Argentina (21/10/2009)

3. Hong Kong (29/11/ 2009)

4. Italy, Bologna (4/11/2009)

5. Israel (9/11/2009)

6. India, Mumbai (11/11/2009)

7. Brazil, Sao Paulo (13/11/2009)

8. South Korea (18/11/2009)

9. Greece, Athens (20/11/2009)

10. Australia, Sydney (24/11/2009);

11. Australia, Melbourne (1/12/2009)

12. Romania, Bucharest (3/12/2009)

13. United Kingdom (15/12/2009)

14. Denmark, Copenhagen (2/12/2009)

15. Spain, Madrid (14/1/2010)

16. Poland, Warsaw (22/1/2010)

17. Malaysia, Kuala Lumpur (27/1/2010)

18. United States, San Francisco $(5 / 2 / 2010)$

19. Germany, Frankfurt (16/3/2010)

20. Hungary, Budapest 


\section{Appendix B}

Descriptive statistics for days in proximity to consultation group meetings ${ }^{206}$ and for days not in proximity to consultation group meetings, from Sep. 23, 2009 to Mar. 10, 2010.

\section{Overall}

Days

169

Visits per day - M

31.36

Visits per day - S.D

\section{In proximity to}

\section{meetings}

Days 46

Visits per day - M 46.13

Visits per day - S.D 19.76

Visits per day - Min

Visits per day - Max
18.78

\section{Not in proximity to meetings}

Days 123

Visits per day - M 25.83

Visits per day - S.D 15.12

Visits per day - Min 3

Visits per day - Max

80

${ }^{206}$ Independent samples T-test revealed $-\mathrm{T}(167)=7.12, \mathrm{p}<0.001$. Cohen's $\mathrm{d}=1.23$, as calculated by subtracting the means and dividing the result by the pooled SD. For various reasons, recent social science literature recommends the use effect size measures (such as Cohen's d), in addition to significance testing, see Jacob Cohen (1994). The earth is round ( $\mathrm{p}<.05), 49$ American Psychologist 997-1003. 


\section{Appendix C}

Mean number of visits per day for each country that had a consultation group meeting, separately for days in proximity to the consultation group meeting and for days not in proximity to the meeting, from Sep. 23, 2009 to Mar. 10, 2010.

\begin{tabular}{|c|c|c|c|c|}
\hline & Country & $\begin{array}{c}\text { Date for the } \\
\text { consultation } \\
\text { group } \\
\text { meeting }\end{array}$ & $\begin{array}{c}\text { Days not in } \\
\text { proximity to the } \\
\text { meeting - mean } \\
\text { visits }\end{array}$ & $\begin{array}{c}\text { Days in } \\
\text { proximity to the } \\
\text { meeting - mean } \\
\text { visits }\end{array}$ \\
\hline 1 & South Africa & $01 / 10 / 09$ & 0.36 & 4.67 \\
\hline 2 & Argentina & 21/10/09 & 0.28 & 6.33 \\
\hline 3 & Italy & $04 / 11 / 09$ & 2.63 & 6.67 \\
\hline 4 & Israel & $09 / 11 / 09$ & 0.17 & 0.67 \\
\hline 5 & India & 11/11/09 & 0.98 & 4.33 \\
\hline 6 & Brazil & 13/11/09 & 0.59 & 2.00 \\
\hline 7 & S. Korea & 18/11/09 & 0.52 & 1.67 \\
\hline 8 & Greece & $20 / 11 / 09$ & 0.37 & 5.67 \\
\hline 9 & Australia & $\begin{array}{l}24 / 11 / 09 \\
01 / 12 / 09\end{array}$ & 1.66 & 8.17 \\
\hline 10 & Hong Kong & 29/11/09 & 0.32 & 0.00 \\
\hline 11 & Denmark & $02 / 12 / 09$ & 0.59 & 2.00 \\
\hline 12 & Romania & $03 / 12 / 09$ & 1.11 & 10.67 \\
\hline 13 & U.K. & $15 / 12 / 09$ & 5.19 & 9.67 \\
\hline 14 & Spain & $14 / 01 / 10$ & 0.79 & 9.67 \\
\hline 15 & Poland & $22 / 01 / 10$ & 0.82 & 3.00 \\
\hline 16 & Malaysia & $27 / 01 / 10$ & 0.20 & $3 \cdot 33$ \\
\hline 17 & U.S. & $05 / 02 / 10$ & 2.99 & 4.67 \\
\hline
\end{tabular}




\section{Appendix D}

The social dynamic of the Wiki process: basic characteristics ${ }^{207}$

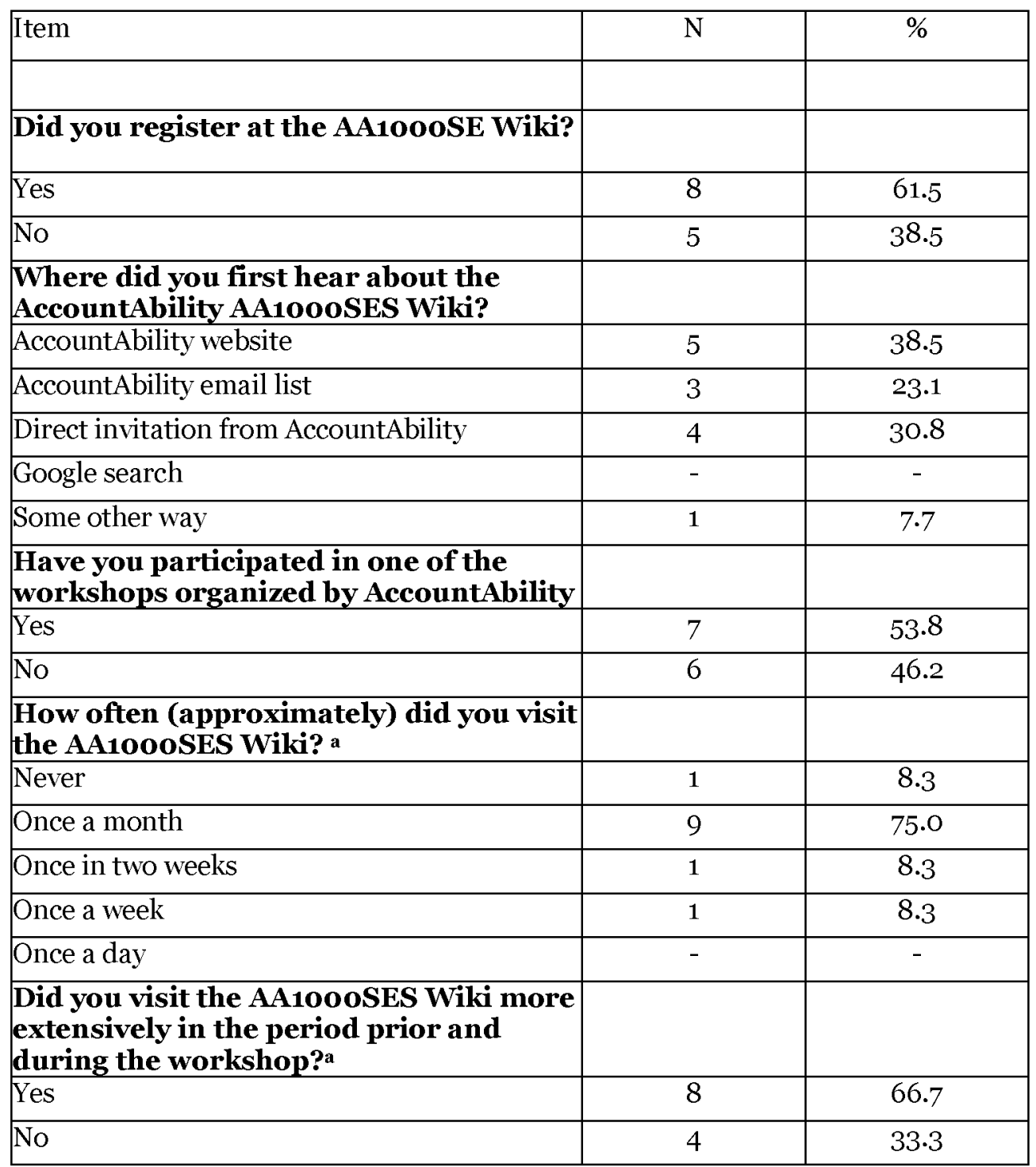

${ }^{207}$ The superscript ' $a$ ' in the table notes that the figures are based on merged data of registered and non-registered users; ' $\mathrm{b}$ ' notes that the data comes from registered users only. 
How often (approximately) did you participate in the actual editing of the AA10ooSES draft text?b

Never

Once a month

Once in two weeks

Once a week

Once a day

50.0

37.5

\begin{tabular}{l|l}
3 & 12.5 \\
\hline
\end{tabular}


[Vol. 9:1

\section{Appendix E}

Descriptive statistics for the items measuring e-literacy

\begin{tabular}{|c|c|c|c|c|}
\hline Item & Mean & SD & Mode & Median \\
\hline PDF & 4.70 & 0.67 & 5 & 5.00 \\
\hline Advanced search & 4.20 & 1.48 & 5 & 5.00 \\
\hline Wiki & 4.00 & 1.05 & 5 & 4.00 \\
\hline RSS & 3.60 & 1.51 & 5 & 4.00 \\
\hline Spyware & 3.50 & 1.65 & 5 & 4.00 \\
\hline Cache & 3.30 & 1.57 & 5 & 3.50 \\
\hline $\begin{array}{c}e-l i t e r a c y \\
\text { composite score) }\end{array}$ & 3.88 & 1.23 & 5 & 4.25 \\
\hline N & & \multicolumn{5}{|c|}{5 -point } \\
\hline Scale & \multicolumn{5}{|c|}{0.95} \\
\hline Cronbach's alpha & & & 5 \\
\hline
\end{tabular}

